DESIGN MANUAL ADJUSTMENTS AND INFRASTRUCTURE NEEDS FOR AUTOMATED VEHICLES: CITY OF TORONTO CONTEXT

\author{
by \\ SHUBHAM BOHRA \\ Bachelor of Technology in Civil Engineering, RTU Kota, India, 2016
}

\author{
A Major Research Project \\ presented to Ryerson University \\ in partial fulfilment of the \\ requirements for the degree of \\ Master of Engineering \\ in the program of \\ Civil Engineering
}

Toronto, Ontario, Canada, 2019

(c) Shubham Bohra, 2019 


\section{Author's Declaration}

I hereby declare that I am the sole author of this project. This is a true copy of the project, including any required final revisions.

I authorize Ryerson University to lend this project to other institutions or individuals for the purpose of scholarly research.

I further authorize Ryerson University to reproduce this project by photocopying or by other means, in total or in part, at the request of other institutions or individuals for the purpose of scholarly research.

I understand that my project may be made electronically available to the public.

Shubham Bohra

Department of Civil Engineering

Ryerson University. 


\title{
DESIGN MANUAL ADJUSTMENTS AND INFRASTRUCTURE NEEDS FOR \\ AUTOMATED VEHICLES: CITY OF TORONTO CONTEXT
}

Master of Engineering, 2019

SHUBHAM BOHRA

Department of Civil Engineering

\begin{abstract}
With the introduction of Automated Vehicles (AVs) in not so distinct future, we need the urban transportation infrastructure to be ready for their sustainable deployment. A key aspect of this readiness is to introduce the right modifications in the road design and the associated adjustments in terms of traffic control. This project focuses on Ontario Traffic Manual and Canadian Capacity Guide. We investigate the adjustments required for interrupted flow and model these adjustments using microsimulation tool VISSIM. Results shows that autonomous vehicles alone even with recommended modifications, without connectivity features would not improve our network as we anticipated, especially at low market penetration rates when Human Drive Vehicles (HDVs) are still on the streets. Furthermore, investments to our current infrastructure need to be made in order to allow communication with the vehicles and keep them updated on the congested, in order to reach the optimal benefit from this technology.
\end{abstract}




\section{Acknowledgements}

I would like to acknowledge my indebtedness and render my warmest thanks to my supervisor, Dr. Bilal Farooq who made this work possible. His friendly guidance and expert advice have been invaluable throughout all stages of the work. I would also wish to express my gratitude to Fahad Khan, Project Lead-City of Toronto Automated Vehicles Division for extended discussions and valuable suggestions which have contributed greatly to the improvement of the thesis. Also, I would like to thank Shadi Djavadian-postdoc at LiTrans, Ryerson University who helped me in improving the report. The thesis has also benefited from comments and suggestions made by Dr. Songnian Li and Dr. Bhagwant Persaud who have read through the project report. I take this opportunity to thank them. This thesis has been written in partial fulfilment of the requirements of the degree of M.Eng. degree in the program of Civil Engineering. I would like to thank Laboratory of Innovations in Transportation (LiTrans) for providing excellent working conditions and Ryerson University for giving this opportunity. 
Table of Contents

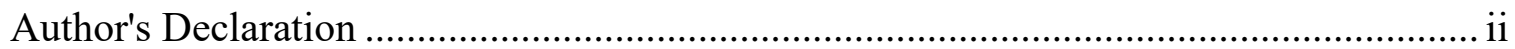

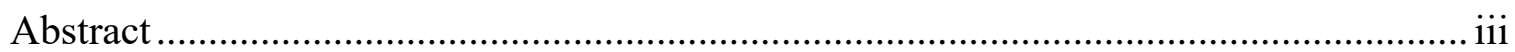

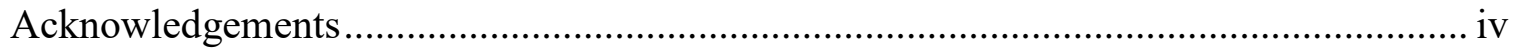

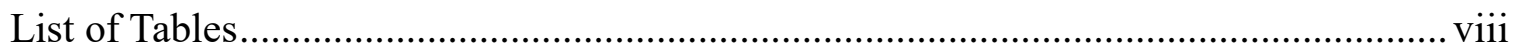

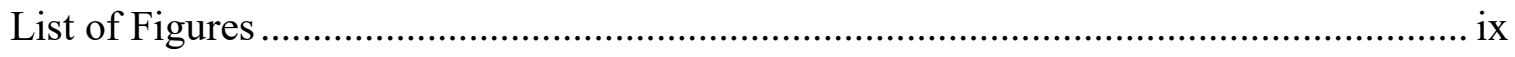

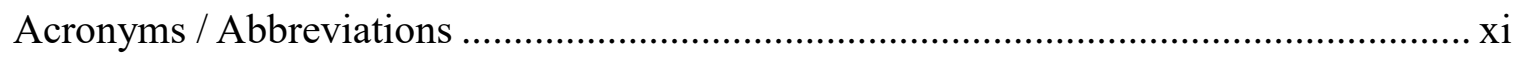

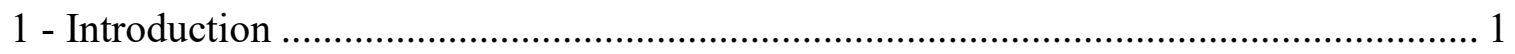

1.1 - Purpose of research .................................................................................. 2

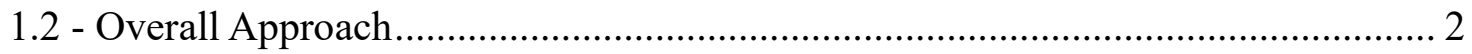

2 - Automated and Connected Vehicles ................................................................... 4

2.1 - Automated Vehicles ................................................................................ 4

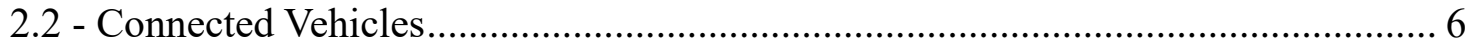

2.3 - Potential Problems with the Introduction of Autonomous Vehicles ...................... 7

2.3.1 - Vehicle to Infrastructure Communication (V2I) ...................................... 7

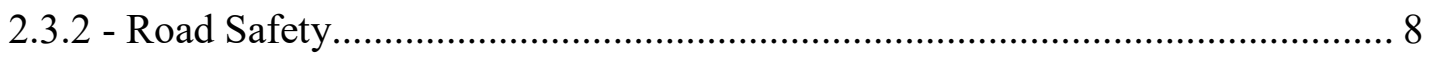

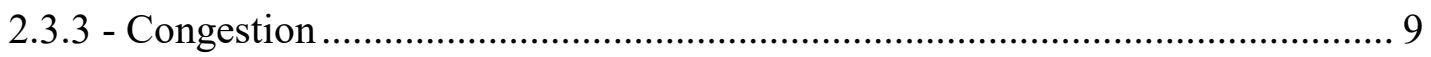

3 - Recommended Design Manual Adjustments and Infrastructure Needs for Automated

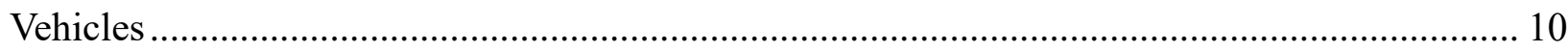




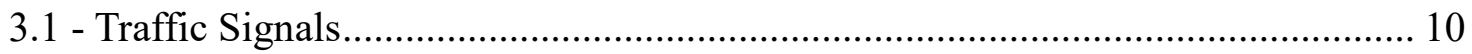

3.1.1 - Current Situation................................................................................. 10

3.1.2 - Future Recommendations ...................................................................... 15

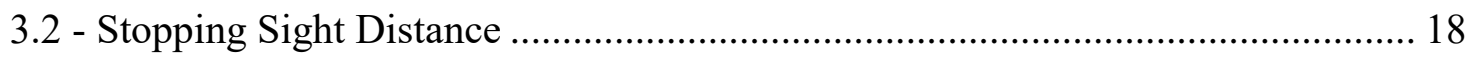

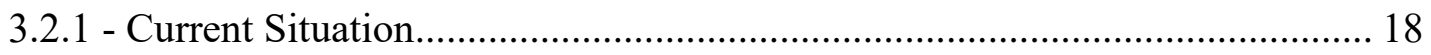

3.2.2 - Future Recommendations ...................................................................... 19

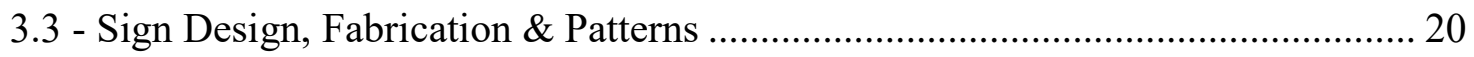

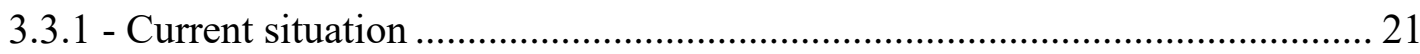

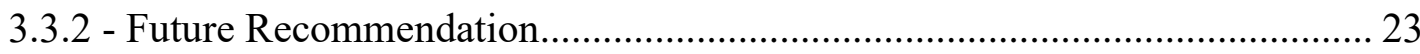

3.4 - Pedestrian Crossing Treatments …………………....................................... 25

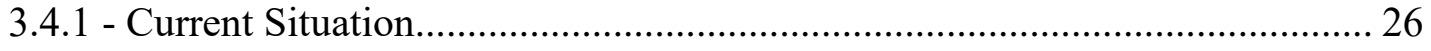

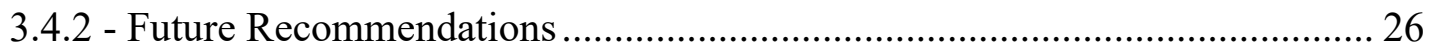

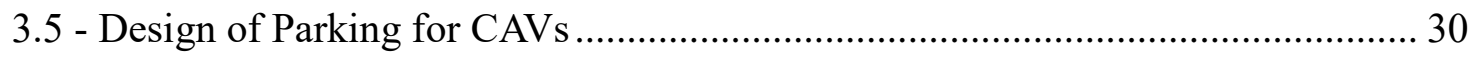

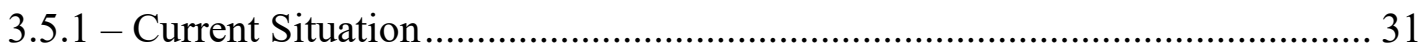

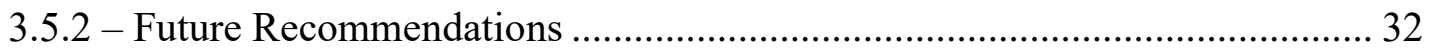

4 - Simulation based Evaluation: Case Study of Downtown Toronto ………………...... 37

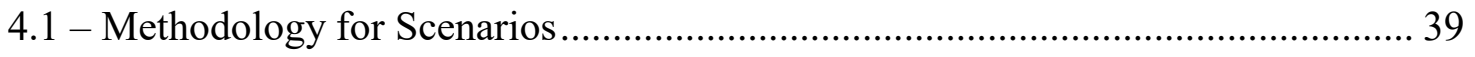

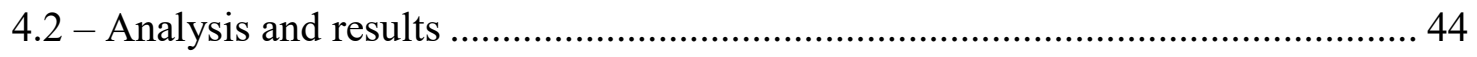

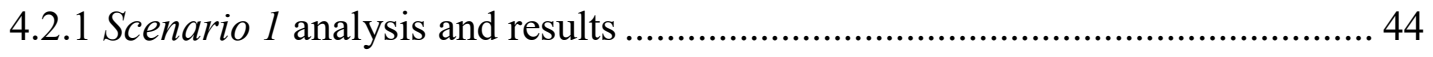

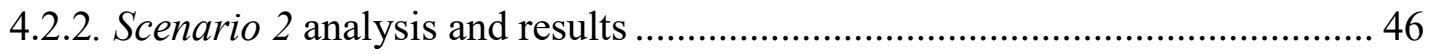


4.2.3. Scenario 3 analysis and results

4.2.4. Scenario 4 analysis and results

4.2.5. Scenario 5 analysis and results 53

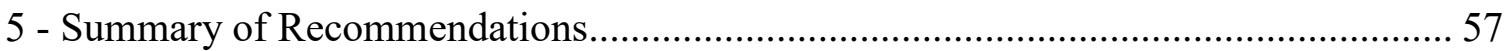

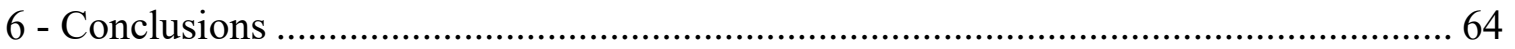

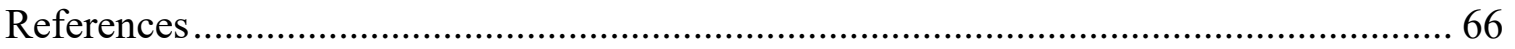




\section{List of Tables}

Table 1 SSD changes with the introduction of AV's ......................................................... 20

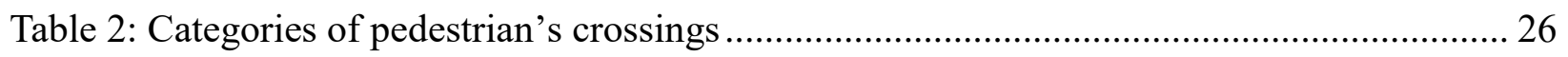

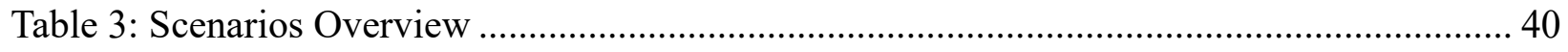

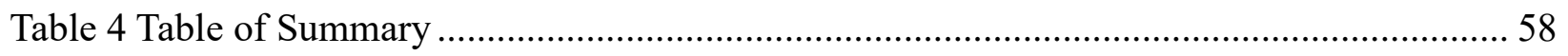




\section{List of Figures}

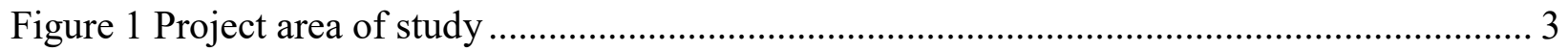

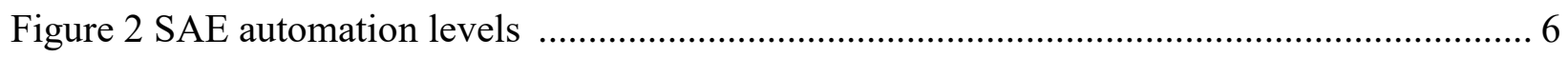

Figure 3 Yellow Change Interval ................................................................................... 14

Figure 4 Example of a poorly maintained sign ............................................................ 22

Figure 5 Conventional parking layout (left) vs possible CAV parking layout (right) ............... 31

Figure 6 Potential layout of CAV carpark, achieving high parking density ............................. 32

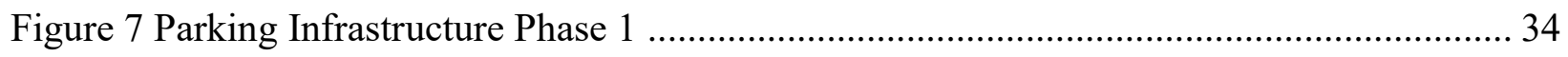

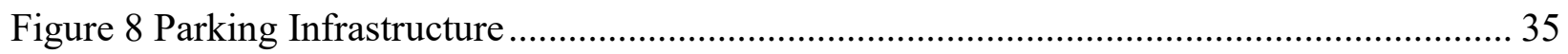

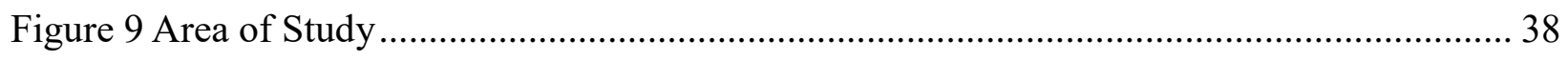

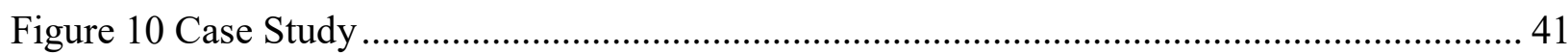

Figure 11 Scenario 1 Maximum Queue Length................................................................ 44

Figure 12 Scenario 1 Number of Vehicles in Queue...................................................... 44

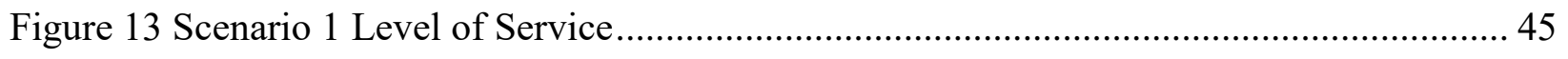

Figure 14 Scenario 2 Maximum Queue Length........................................................... 46

Figure 15 Scenario 2 Number of Vehicles in Queue....................................................... 47

Figure 16 Scenario 3 Maximum Queue Length.......................................................... 48

Figure 17 Scenario 3 Number of Vehicles in Queue.......................................................... 49

Figure 18 Dundas St at University Avenue (satellite view) .............................................. 50

Figure 19 Scenario 4 Maximum Queue Length.......................................................... 51

Figure 20 Scenario 4 Effect of Design speed change ..................................................... 51

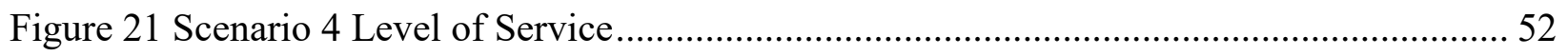

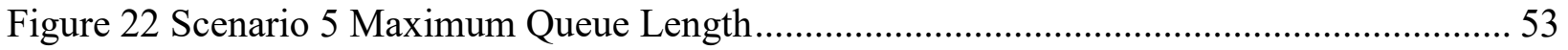


Figure 23 Scenario 5 Change in queue length after cycle length optimization .....

Figure 24 Scenario 5 Vehicle Delay after changes in cycle length ......................................... 55

Figure 25 Scenario 5 Stop Delay after changes in cycle length ........................................... 55 


\section{Acronyms / Abbreviations}

\begin{tabular}{|l|l|}
\hline AV & Autonomous Vehicles \\
\hline CV & Connected Vehicles \\
\hline CAV & Connected Autonomous Vehicles \\
\hline HDV & Human Driven Vehicles \\
\hline NHTSA & Market Penetration Rates \\
\hline V2V & Transportation's National Highway Traffic Safety Administration \\
\hline V2I & Vehicle to Vehicle \\
\hline V2C & Vehicle to Infrastructure \\
\hline V2P & Vehicle to Cloud \\
\hline V2X & Vehicle to Pedestrians \\
\hline ACC & Vehicle to Everything \\
\hline OTM & Adaptive Cruise Control \\
\hline LOS & Ontario Traffic Manual \\
\hline SSD & Level of Service \\
\hline PSD & Stopping Sight Distance \\
\hline DSD & Passing Sight Distance \\
\hline PVSD & Decision Sight Distance \\
\hline ISD & Preview Sight Distance \\
\hline IMUs & Intersection Sight Distance \\
\hline CAN & Inertial Measurement Units \\
\hline C-ITS & controller area network \\
\hline ADAS & Co-operative Intelligent transport systems \\
\hline APS & Advanced Driver Assistance Systems \\
\hline HCM & Assisted Parking System \\
\hline OTM & Highway Capacity Manual \\
\hline TAC & Ontario Traffic Manual \\
\hline
\end{tabular}




\section{1 - Introduction}

Congestion on road networks undermines the people and goods mobility in major cities. Traditionally, the congestion problem on surface streets was dealt by adding more lanes and new links to the existing transportation network. Since such a solution can no longer be considered, given the limited availability of space in urban centers, greater emphasis is nowadays placed on traffic management through the implementation and operation of intelligent transportation systems $[1]$.

Autonomous vehicles represent a potentially disruptive yet beneficial change to our transportation system. This new technology has the potential to impact travel behavior, congestion vehicle safety, and land use if applied with perfection and a good penetration of market share. AVs impacts in the form of crash savings, travel time reduction, fuel efficiency and parking benefits are estimated to approach $\$ 2,000$ to per year per $\mathrm{AV}$, and may eventually approach nearly $\$ 4,000$ when comprehensive crash costs are accounted for [2].

When investigating a relatively new technology such as AV's, many uncertainties revolve around the impacts and interactions with other components of the transportation system such as modes, infrastructures, networks, flows [3]. From how the vehicle will operate on the road with other vehicles to how it will react to pedestrians, along with the vehicle reacting to different signages. This gives researcher different aspects to look into such as standardization of the technology, implementation, cost of the technology, the effect on the environment, etc.

The objective of this project is to provide a discussion and review the potential impacts of AV's to enhance the roadway safety and capacity while reducing the traffic congestion. In order to achieve that we studied the influence of AV technologies on traffic flow behavior and pointed out the areas which needs update in the current design manual. Also, to get a better understanding of 
traffic flow, delay and collision we simulated the current traffic volume, 10\% growth rate and $20 \%$ growth rate at varying market penetration rates using microsimulation tool VISSIM. Results show that the main benefits of $\mathrm{AVs}$ are that they can drive closer to each other and they require lower reaction time. This reductions in safe distance and reaction time, results in higher capacity of the road and significant improvement. Also, in order to attain the complete benefits of the AVs infrastructure needs to be updated to accommodate CAV's since after a certain grow

\section{1 - Purpose of research}

The purpose of this research is to explore what changes could be made in the Ontario Traffic Manual and what are the needs in terms of infrastructure to accommodate automated vehicles on Ontarian streets in the near future. Different market penetration rates for AVs were analyzed and observed using micro-simulation and optimization to foresee their affect.

\section{2 - Overall Approach}

In order to reach our objectives for this research a deep understanding of the current traffic regulations and manuals had to be established before developing recommendations and simulating different scenarios in order to evaluate these recommendations. Since federal regulations necessitate that all changes to existing traffic systems be checked for operational efficiency simulation models are becoming common assessment tools to verify the effectiveness of these changes. Traffic Simulation Software's are widely used for traffic and transport planning studies, because they give you a realistic and detailed overview about the status quo of the traffic flow and impacts, with the possibilities to define multiple what-if scenarios including the addition of AVs [4]. In this study we focus on AVs impacts on our current traffic manuals and existing infrastructure. For our simulation we assumed that three regimes of $\mathrm{AVs}-30 \%, 50 \%$ and $70 \%$. The reason we chose $30 \%, 50 \%$ and $70 \%$ was to look at having low, medium and high MPR scenarios. Figure 1 
gives a general overview of our methodology. Furthermore, the steps in detail are explained as follows:

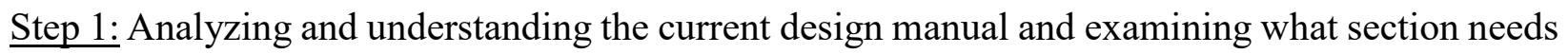
to be updated to incorporate the operations of automated vehicles on Ontarian roads.

Step 2: Undergoing a thorough literature review on what optimal implementation changes can be implemented to accommodate the introduction of Autonomous vehicles

Step 3: Developing a case study to show the effect of the different design changes in the intersection; that requires collecting data on real intersections and simulating the effects of different scenarios on traffic flow related indicators

Step 4: Communicating with decision makers in the intelligent transportation planning sector to discuss the feasibility of implementation

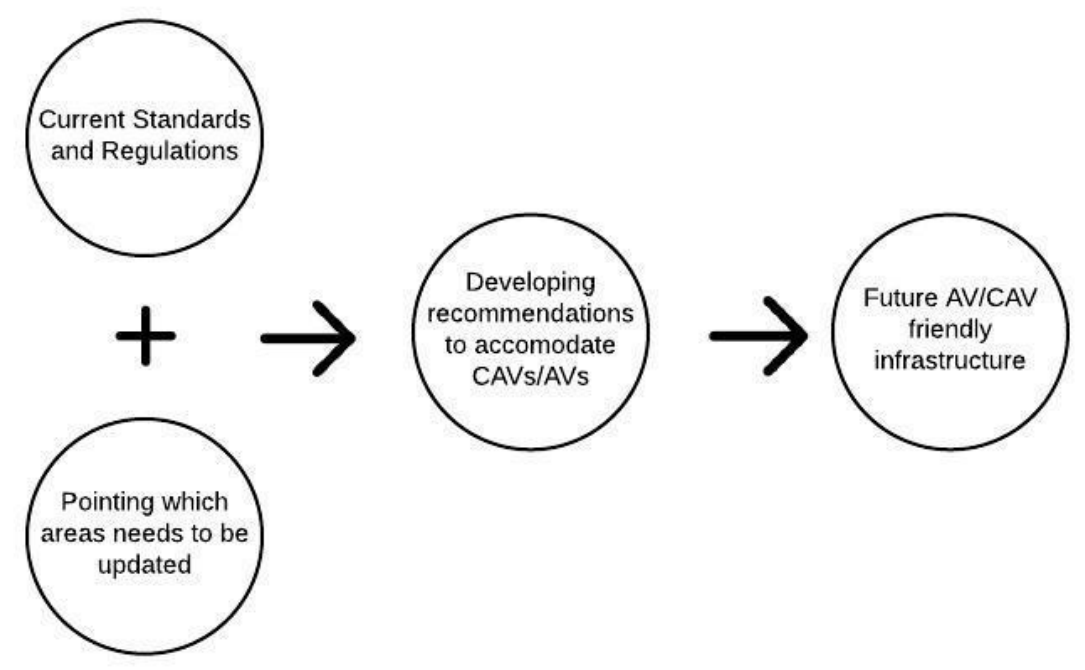

Figure 1 : Project area of study 


\section{2 - Automated and Connected Vehicles}

Automated and connected vehicle technologies are among the most heavily researched automotive technologies. The vehicle technologies currently available are only a fraction of what is being developed for the future. The technologies for autonomous cars, connected cars, and advanced driver assistance systems overlap, below is an overview of the technologies, definitions, benefits and challenges of this emerging sector [5].

\section{1 - Automated Vehicles}

Fully automated, autonomous, or "self-driving" vehicles are defined by the U.S. Department of Transportation's National Highway Traffic Safety Administration (NHTSA) as "those in which operation of the vehicle occurs without direct driver input to control the steering, acceleration, and braking and are designed so that the driver is not expected to constantly monitor the roadway while operating in self-driving mode." There have been multiple definitions for various levels of automation, for the sake of standardization, and to aid clarity and consistency, NHTSA has adopted the SAE (figure 2) International definitions for levels of automation. These definitions divide vehicles into levels based on "who does what, when."

In SAE's automation level definitions, "driving mode" means "a type of driving scenario with characteristic dynamic driving task requirements (e.g., expressway merging, high speed cruising, low speed traffic jam, closed-campus operations, etc.)" [6].

- Level 0: Automated system issues warnings and may momentarily intervene but has no sustained vehicle control.

- Level 1 ("hands on"): The driver and the automated system share control of the vehicle. Examples are Adaptive Cruise Control (ACC), where the driver controls steering and the automated system controls speed; and Parking Assistance, where steering is automated 
while speed is under manual control. The driver must be ready to retake full control at any time. Lane Keeping Assistance (LKA) Type II is a further example of level 1 self-driving.

- Level 2 ("hands off"): The automated system takes full control of the vehicle (accelerating, braking, and steering). The driver must monitor the driving and be prepared to intervene immediately at any time if the automated system fails to respond properly. The shorthand "hands off" is not meant to be taken literally. In fact, contact between hand and wheel is often mandatory during SAE 2 driving, to confirm that the driver is ready to intervene.

- Level 3 ("eyes off"): The driver can safely turn their attention away from the driving tasks, e.g. the driver can text or watch a movie. The vehicle will handle situations that call for an immediate response, like emergency braking. The driver must still be prepared to intervene within some limited time, specified by the manufacturer, when called upon by the vehicle to do so.

- Level 4 ("mind off"): As level 3, but no driver attention is ever required for safety, e.g. the driver may safely go to sleep or leave the driver's seat. Self-driving is supported only in limited spatial areas (geofenced) or under special circumstances, like traffic jams. Outside of these areas or circumstances, the vehicle must be able to safely abort the trip, e.g. park the car, if the driver does not retake control.

- Level 5 ("steering wheel optional"): No human intervention is required at all. An example would be a robotic taxi. 

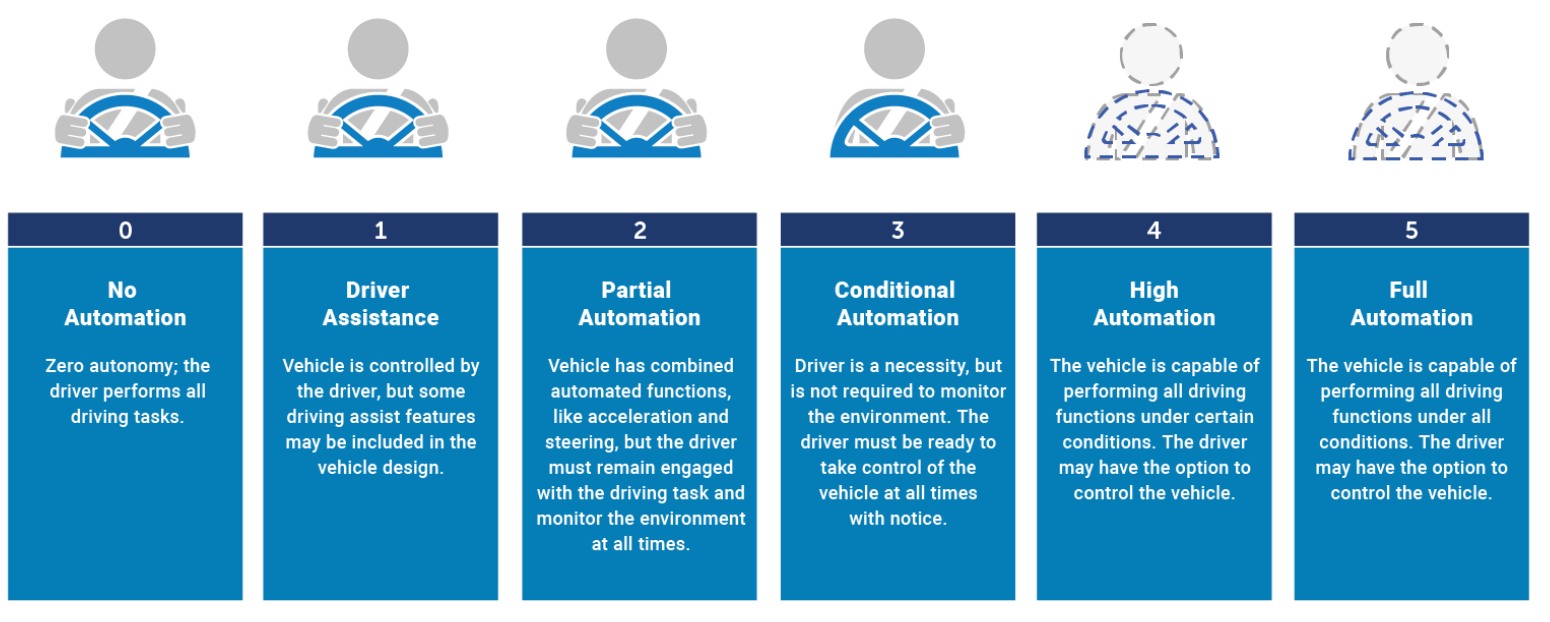

Figure 2 SAE automation levels [7]

\section{2 - Connected Vehicles}

The term connected vehicles refers to applications, services, and technologies that connect a vehicle to its surroundings. A connected vehicle includes the different communication devices (embedded or portable) present in the vehicle, that enable in-car connectivity with other devices present in the vehicle and/or enable connection of the vehicle to external devices, networks, applications, and services. [8].

Connected vehicles use several different communication technologies such as dedicated shortrange communications (DSRC) that permit two-way medium-range wireless connectivity similar to Wi-Fi and cellular 5G technology to communicate with other cars on the road (vehicle-tovehicle [V2V]), roadside infrastructure (vehicle-to-infrastructure [V2I]), and the "Cloud" [V2C]. These technologies can be used to not only improve vehicle safety, but also to improve vehicle efficiency and commute times.[9]

Listed below are the types of communication, with links to more information, and some of the benefits of connected vehicles:

- V2I- Vehicle to Infrastructure 
- $\quad \mathrm{V} 2 \mathrm{~V}$ - Vehicle to Vehicle

- $\quad$ V2C- Vehicle to Cloud

- V2P- Vehicle to Pedestrians

- Vehicle to Everything

\section{3 - Potential Problems with the Introduction of Autonomous Vehicles}

While the introduction of self-driving cars offers many potential benefits, the rise in automated car technology also comes with its own set of issues. Technology is never perfect, and computers can be compromised from a security standpoint. Furthermore, while driverless cars will make our roads safer, they may also result in less desired societal consequences, such as higher unemployment rates[10].

\subsection{1 - Vehicle to Infrastructure Communication (V2I)}

When we talk about the human driven vehicles they rely mostly on the eyes and what they "see" to obey laws and avoid collisions on the road. But when we talk about the AVs, they rely on a series of sensors that can help them to understand the environment in which they are traveling. For AVs a combination of LiDAR sensors, radar, ultrasonic and imaging is used to form digital road maps ahead for them help it "see" where it is going [11].

While AV's are emerging, V2I technologies are essential for them. The main problem is that the vehicle technology is advancing way faster than the infrastructure can adapt, since connected autonomous vehicles are being manufactured with no current update on the infrastructure which means that the vehicle won't have the ability to connect. to our current network [12]. 


\subsection{2 - Road Safety}

The researchers claims that $90 \%$ of crashes are due to human error, autonomous vehicles will reduce the crash rates [2], but this overlooks the additional risks these technologies can introduce [13]. Hardware and software failures includes the failure of complex electronic systems, and even small vehicle operating system failures - a false sensor, distorted signal, or software error - can have catastrophic results [14]. Self-driving vehicles will certainly have failures that contribute to crashes, the question is their frequently compared with human drivers. Also, self-driving technologies can be manipulated for amusement or crime which could result in larger consequences [15]. There is a tendency when travelers feel safer, they often take additional risks, called offsetting behavior or risk compensation. For example, if autonomous vehicles are considered very safe, passengers may reduce seatbelt use, and other road users may take greater risks [16] what Toyota Research Institute Director Gill Pratt describes as "over-trusting" technology [17]. Many potential benefits, such as reduced congestion and pollution emissions, require platooning [7]. Platooning means vehicles operating close together at high speeds on dedicated lanes, which can introduce new risks, such as human drivers joining platoons and increased crashes severity. With the improvement in convenience and comfort autonomous vehicles may increase total vehicle travel and hence there will be rise in the crash exposure [18]. There might be some difficulty to AVs in respect to detecting, communicating with and accommodating pedestrians, bicyclists and motorcycles. This will give rise to additional risks to the non-auto travelers [9]. 


\subsection{3 - Congestion}

Multiple studies have investigated the potential for AVs to reduce congestion under differing scenarios. Under various levels of AV adoption congestion savings due to ACC measures and traffic monitoring systems could smooth traffic flows by seeking to minimize accelerations and braking in freeway traffic. This could increase fuel economy and congested traffic speeds by $23-39 \%$ and $8-13 \%$, respectively, for all vehicles in the freeway travel stream, depending on V2V communication and how traffic-smoothing algorithms are implemented [20].

If vehicles are enabled to travel closer together, the system's fuel and congestion savings rise further, and some expect a significant increase in highway capacity on existing lanes [11], estimate that cooperative adaptive cruise control (CACC) deployed at 10\%, 50\%, and 90\% marketpenetration levels will increase lanes' effective capacities by around $1 \%, 21 \%$ and $80 \%$, respectively [21]. Gap reductions coupled with near-constant velocities produce more reliable travel times - an important factor in trip generation, timing, and routing decisions. Similarly, shorter headways between vehicles at traffic signals (and shorter start-up times) mean that more AVs could more effectively utilize green time at signals, considerably improving intersection capacities. 


\section{3 - Recommended Design Manual Adjustments and Infrastructure Needs for Automated}

\section{Vehicles}

The way vehicles are operated is revolutionizing day by day, in the coming years we can see "self-driving" vehicles travelling alongside the human-driven vehicles [21]. In the case of selfdriving vehicles, they act differently than the human-driven vehicles and the human behavior does not play any role when the vehicle makes any decisions to stop or perform a turning maneuver [22]. On the other hand, when we talk about the signal timing parameters i.e. duration of green, amber, and red clearance times, human perception time and reaction time is taken into consideration. All the recommendations in this document are developed on the basis of extensive literature review and prior research work by other researchers.

\section{1 - Traffic Signals}

In this section the signal timing parameters are reviewed, taken into consideration both human driven as well as self-driven vehicles. Also, safety and efficiency are the factors kept into account at signalized intersection. When we talk about human driven vehicles the main focus is on the driver who is taking control of the vehicle. There are many psychological, environmental, vehicle design factors and road regulations which influences the driver's performance. For instance, driver perception and reaction time, along with factors such as drivers age, fatigue or alcohol consumption.

\subsection{1 - Current Situation}

In order to calculate yellow change interval driver's perception reaction time is taken as 1 second minimum as mentioned in traffic engineering handbook $7^{\text {th }}$ edition [23]. In certain special conditions typically with isolated rural or high-speed locations with the posted speed of $80 \mathrm{~km} / \mathrm{hr}$ 
or higher, the authorities may choose to go for a longer perception reaction time as mentioned in Ontario Traffic Manual Book 12 [24].

Furthermore, the driver age, fatigue and various forms of distracted and careless driving does not apply for the AV. This is because the algorithms running on AV allows it to run either at or below the posted speed limit. This allows AV to conform to the traffic laws and all the decisions are made within 0.83 seconds. [22]

Moreover, regarding design speed road authorities usually use the $85^{\text {th }}$ percentile speed in order to calculate the yellow interval time, the passage time and the location of the distance loop detectors. However, the $85^{\text {th }}$ percentile speed is not the accurate estimation. In the absence of field measurement, the $85^{\text {th }}$ percentile speed is approximately $11 \mathrm{~km} / \mathrm{hr}$ above the posted speed limit for the through traffic vehicles, and for left turning vehicles it is approximately $8 \mathrm{~km} / \mathrm{hr}$ below the posted speed limit as per the Ontario Traffic Manual Book 12 [24].

Additionally, the intersection geometric design has an impact on the visibility of signal indications, the stopping sight distance and the signal timing design [25]. It is important to consider the factors above when calculating the traffic control signal parameters. Otherwise, the traffic control signal will operate improper timing, resulting in unsafe conditions (collisions), low LOS, wasted commuter times and increases in fuel consumption.

One of the most important factors affecting the performance of an intersection is the signal timing parameters. There can be six basic timing (parameters which can be used to develop the signal timing plans for a standard eight- phase intersection. The following parameters are typically programmed for each phase in the traffic signal controllers (NEMA \&170 specifications):

\section{Minimum Green Time}


The minimum green parameter represents the least amount of time that a green signal indication is displayed when a signal phase is activated [24]. Drivers do not expect an immediate termination of a signal display that has just started. Therefore, a minimum interval time is used in order to avoid violating driver expectations. Since the signals work on the volume-density mode of operation, an added initial feature could be used with the actuated phases to increase the minimum green time in order to account for the vehicles which are stored between the longdistance detector and the stop line at the onset of green. The added initial feature increases the minimum green as necessary based on the vehicles that arrived while the signal is not green. Without the "added initial" feature, the minimum green would have to be set high to clear all stored vehicles. While calculating the effective green time for a phase a start-up time of up to 4 seconds is usually considered [26].

\section{Passage Time (Vehicle Extension Time)}

Passage time, sometimes called passage gap, vehicle extension, or unit extension, is used to extend the green interval based on the detector status once the phase is green. This parameter extends the Green Interval for each vehicle actuation up to the Maximum Green. It begins timing when the vehicle actuation is removed. This extension period is subject to termination by the Maximum Green timer or a Force Off [25]. Passage time is used to find a gap in traffic for which to terminate the phase, essentially it is the setting that results in a phase ending prior to its maximum green time during isolated operation (figure 4).

The passage time is usually based on the detection zone length, the number of lengths served by the phase and the vehicle speed. On high speed approach the passage time should be calculated as it should be enough for the high-speed vehicle to stop safely before the stop line. The beginning of the decision zone is the proper location for the detection zone. 5.5 second and 2.5 second of the 
travel time prior to the stop line is the limit of the decision zone. To assist driver of high-speed vehicle multiple detectors could be placed upstream of the stop line beginning of the decision zone. 85th percentile speed is considered for the calculation of passage time value and the position of the detectors.

\section{Maximum Green Time}

The maximum green time parameter defines the maximum amount of time that a green signal indication can be displayed in the presence of a conflicting demand. Generally, the green signal for the left turn phase ranges $15-30$ s, 20-40s for the through phase and 30-60s for through passing a major intersection. Capacity analysis method is used to calculate the duration of maximum green time in applicable actuated phase [27]. In case of isolated intersection, the green time should be long enough to clear the traffic volume and short enough to reduce delay in the opposing traffic movement.

\section{Yellow Change Interval}

Yellow change interval is the indication for the upcoming presentation of the red signal. It also works as an alert for the traffic to clear the intersection before the opposing traffic receives the green indication [26].

Under the permissive yellow law, the yellow change interval has two purpose:

A) It allows the approaching vehicle that can make a comfortable stop to stop

B) It allows vehicle that couldn't make a comfortable stop to clear the intersection

The ITE kinematic equation is the recommended and commonly used method for calculating the yellow change interval [23]

$$
\mathrm{Y}=\mathrm{T}+\mathrm{V} /(2(\mathrm{a}+\mathrm{Gg}))
$$

Where: 
$\mathrm{Y}=$ length of the yellow change interval (sec)

$\mathrm{T}=$ perception - reaction time, generally assumed as 1 second

$\mathrm{V}=85^{\text {th }}$ percentile approach speed $(\mathrm{km} / \mathrm{h})$

$' \mathrm{a}=$ average deceleration rate, generally assumed $(11 \mathrm{~km} / \mathrm{h} / \mathrm{s})$

' $\mathrm{g}$ = approach grade (percentage divided by 100, negative for downgrade)

$\mathrm{G}=$ acceleration due to gravity $(35.3 \mathrm{~km} / \mathrm{h} / \mathrm{s})$

The AV reaction time is a split second, and it travels at a speed equal to or below the posted speed limit. Therefore, if the duration of the yellow interval is enough for conventional vehicles, it will be enough for the $\mathrm{AV}$ as well (figure 3).

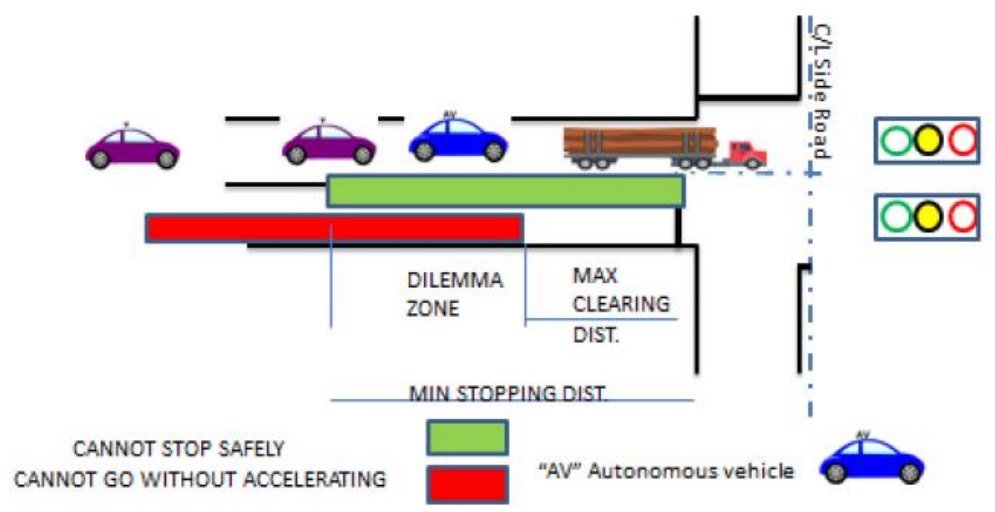

Figure 3 Yellow Change Interval [28]

\section{$\underline{\text { Red Clearance Interval }}$}

The red clearance interval can be used to allow a brief time to elapse after the yellow interval, during which the signal heads associated with the ending phase and all

Conflicting phases display a red indication [26].

The red clearance is a safety related parameter. The following equation is

Recommended for calculating the red clearance interval [23]:

$\mathrm{R}=3.6(\mathrm{~W}+\mathrm{L}) / \mathrm{V}$

Where, 
$\mathrm{R}=$ Red clearance interval (seconds)

$\mathrm{W}=$ Intersection width $(\mathrm{m})$

$\mathrm{L}=$ Vehicle length, generally assumed to be $6 \mathrm{~m}$

$\mathrm{V}=85^{\text {th }}$ percentile approach speed $(\mathrm{km} / \mathrm{h})$

3.1.2 - Future Recommendations

Minimum Green Time Recommendation

The start-up time for an AV should be a programmable feature. With a small start-up time there could be conflict between $\mathrm{AV}$ entering the intersection on the onset of green and $\mathrm{CV}$ entering from the earlier phase. Therefore, a delay time should be automatically programmed to the startup time for AV. The local driving conditions and the driver behaviour should be factor for the adjustable delay time[28] .

Passage Time Recommendation

The AV will be able to decide if it should stop or go due to the negligible amount of the decision time required. A closely following HDV could expose the AV for a rear end collision due to miscalculation or misjudgement of the human driven vehicle due to response time. In order counter this the response time in this scenario for $\mathrm{AV}$ should be delayed so AV performs as a skilled defensive driver. The high-speed approaches, advanced detection method may be utilized where vehicle with a defined area and with determined min and mix speed value is measured. The detection method is capable of dynamic estimate of the arrival of each vehicle and providing individual protection. 

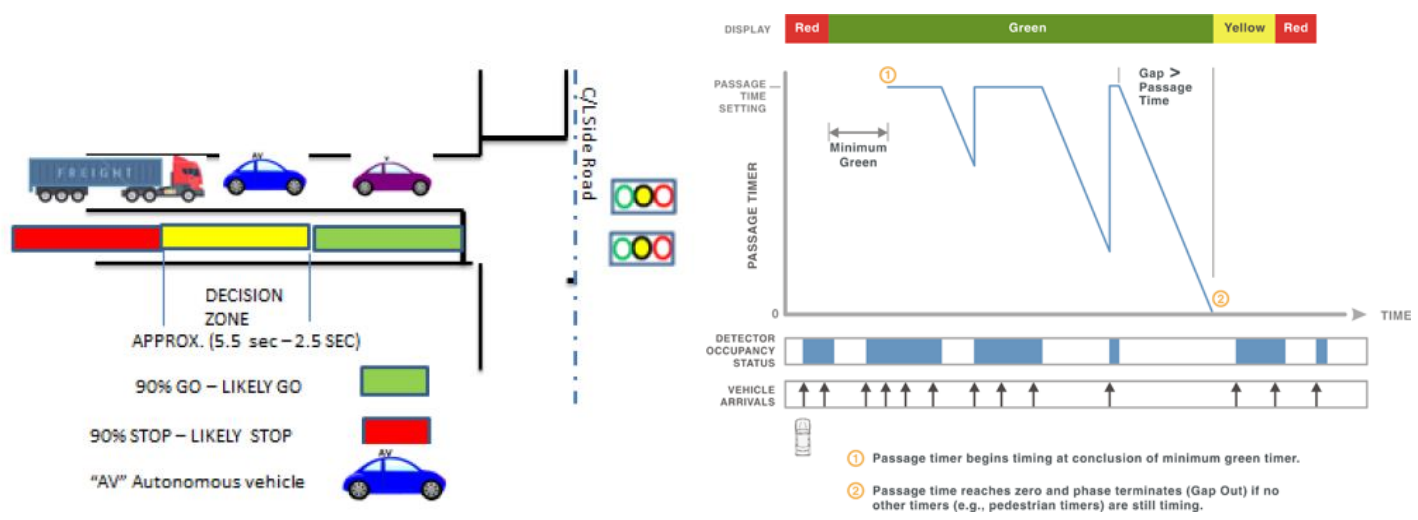

Figure 4 Passage Time [28]

\section{> Maximum Green Recommendation}

AVs can maintain posted or higher than the posted speed limit. However, AVs are programmed to obey the speed limit and could result in lager gaps and termination of the phase early. The traffic controller should be programmed to provide reasonable passage time based on the field measurements. Also, the saturation flow rates should be based on the average time headway of both the AVs and HDVs.

\section{Yellow Change Interval Recommendation}

If the duration of the installed yellow change interval is less than the calculated value from equation, the AV might not be able to stop comfortably at the stop line or it might cross the stop line on red. Road authorities should ensure that the installed yellow change interval is adequate.

Also, an instant reaction of the AV to the onset of the yellow signal indication could result in a rear-end collision if a conventional vehicle is following too closely. A possible solution to this scenario is to calibrate the AV reaction time (adjustable delay time) to the onset of the yellow signal indication based on roadway conditions [28]. 


\section{Red Clearance Interval Recommendation}

To avoid a conflict between the AV clearing the intersection and a conventional vehicle entering the intersection at the onset of green, the use of the posted speed limit is recommended instead of the $85^{\text {th }}$ percentile speed when calculating the red clearance interval.

To summarize all the recommendations, here are key recommendations for signal timings:

- The current methods of calculating the minimum and maximum green time parameters are acceptable for both conventional vehicles and the AV.

- The programming of the on-board computers shall consider deploying adjustable delay times based on local driving conditions (provincial, territorial, and municipal) and driver behavior.

- The calculation of the passage time parameter and associated detection zones based on a fixed approach speed is problematic. It does not serve the needs of the AV on high speed roadways. At high speed roadways, the use of advanced detection methods (e.g. wide area detection utilizing radar-based technology) will better serve conventional vehicles as well as the $\mathrm{AV}$.

- The duration of the yellow change interval should be calculated according to the ITE's kinematic equation. A shorter duration of the yellow change interval will adversely impact the safety of both conventional vehicles and the AV.

- The red clearance time should be calculated using the posted speed limit instead of the $85^{\text {th }}$ percentile speed.

- If the AV travelling speed is below the design speed, it will disrupt the progression of traffic flow because it will be travelling outside the progression band. It is necessary to coordinate 
the green time at closely spaced signalized intersections, taking into consideration the prevailing travel speeds of both conventional vehicles and the AV.

\section{2 - Stopping Sight Distance}

Sight distance is the length of the roadway ahead that is visible to the driver. It is a fundamental design element in the safe and efficient operation of a highway. Five basic types of sight distances must be considered in design:

(1) stopping sight distance (SSD), applicable on all highways

(2) passing sight distance (PSD), applicable only on two-lane highways

(3) decision sight distance (DSD), needed at complex locations

(4) preview sight distance (PVSD), applicable to horizontal curves, especially those combined with vertical curves

(5) Intersection sight distance (ISD), needed for all types of intersections.

In addition, a special type of sight distance (called head-on sight distance) that may be needed when parking occurs on both sides of a residential street has been addressed by Gattis [29].

\subsection{1 - Current Situation}

Stopping sight distance is the distance that enables a vehicle traveling at or near the design speed to stop before reaching a stationary object in its path. The SSD in feet is computed by

$$
S S D=1.47 V t+\frac{V^{2}}{30[(a / 32.2)+G]}
$$

$\mathrm{t}=$ the brake reaction time $(\mathrm{sec})$

$\mathrm{V}=$ the design speed (mph) 
$\mathrm{a}=$ the deceleration rate $(\mathrm{ft} / \mathrm{sec} 2)$

$\mathrm{G}=$ the percent of grade divided by 100 (positive for upgrade and negative for downgrade

The recommended design criterion for brake reaction time is $2.5 \mathrm{sec}$, which exceeds the $90^{\text {th }}$ percentile of reaction time for all drivers. The recommended design deceleration rate is 11.2 $\mathrm{ft} / \mathrm{sec} 2$, which is the comfortable deceleration rate for most drivers on wet surfaces [27].

\subsection{2 - Future Recommendations}

Time to respond varies greatly across different tasks and even within the same task under different conditions. It can range from 1.5 second to many seconds. When a person responds to something s/he hears, sees or feels, the total reaction time can be decomposed into a sequence of components as follows [30]:

$>$ Mental Processing Time

This is the time it takes for the responder to perceive that a signal has occurred and to decide upon a response. For a human driven vehicle it various depending on visibility, driver gender, driver age, roadway grade, mean approach speed, platooning scenarios (leading, following, or alone) [31]. However, for AV's there isn't any driver, so this component can be considered equal to zero or a value in few milliseconds.

\section{Movement Time}

This component for humans occurs once a response is selected. The responder will perform the required muscle movement. For example, it takes time to lift the foot off the accelerator pedal, move it laterally to the brake and then to depress the pedal. However, for AV's there isn't any human responder it's the vehicle itself that will perform the movement required.

Device Response Time

Mechanical devices take time to engage, even after the responder has acted. For example, a driver stepping on the brake pedal does not stop the car immediately. Instead, the stopping is a 
function of physical forces, gravity and friction. In experimental setting, it was found that almost half the distance is created by driver reaction time which is a factor we can eliminate in AV's since there will be no driver [32]. By applying the SSD equation [27] for the recommended perception reaction time by TAC as 2.5 secs and comparing it with assumed perception reaction for AV's as 1 second and 0.30 seconds and comparing them in Table 1 below:

Table 1 SSD changes with the introduction of AV's

\begin{tabular}{|c|r|r|r|r|r|r|}
\hline $\begin{array}{l}\text { Design } \\
\text { Speed } \\
(\mathrm{mph})\end{array}$ & $\mathrm{t}(\mathrm{sec})$ & $\begin{array}{l}\text { SSD } \\
\text { Calculated } \\
(\text { feet })\end{array}$ & $\mathrm{t}(\mathrm{sec})$ & $\begin{array}{l}\text { SSD } \\
\text { Calculated } \\
\text { (feet) }\end{array}$ & $\mathrm{t}(\mathrm{sec})$ & $\begin{array}{l}\text { SSD } \\
\text { Calculated } \\
\text { (feet) }\end{array}$ \\
\hline 40 & 2.5 & 300.6 & 1 & 212.4 & 0.3 & 171.2 \\
\hline 50 & 2.5 & 423.7 & 1 & 313.5 & 0.3 & 262 \\
\hline 60 & 2.5 & 566.0 & 1 & 433.7 & 0.3 & 372 \\
\hline 70 & 2.5 & 727.6 & 1 & 573.2 & 0.3 & 501.2 \\
\hline
\end{tabular}

\section{3 - Sign Design, Fabrication \& Patterns}

The specific purpose of OTM book 2 is to provide practical guidelines and sign patterns for the design and fabrication of traffic signs. It addresses the design and fabrication of traffic signs. In the upcoming sections we will be investigating the changes and additions that should be made to accommodate the introduction of autonomous vehicles. However, before stating what modifications need to be made, a detailed overview of how AV sensors operate to detect signs and markings should be addressed.

As an overview, automotive sensing falls into three main categories: self-sensing, localization, and surrounding-sensing. Self-sensing uses proprioceptive sensors to measure the current state of the ego-vehicle, including the vehicle's velocity, acceleration, yaw, and steering 
angle. Proprioceptive information is commonly determined using pre-installed measurement units, such as odometers, inertial measurement units (IMUs), gyroscopes, and information from the controller area network (CAN) bus.

Localization, using external sensors such as GPS or dead reckoning by IMU readings, determines the vehicle' s global and local position. Lastly, surrounding-sensing uses exteroceptive sensors to perceive road markings, road slope, traffic signs, weather conditions, the state (position, velocity, acceleration, etc.) of obstacles including other vehicles, and even the state of the driver (vigilance, drowsiness, fatigue, boredom due to monotony, etc.) [33].

\subsection{1 - Current situation}

Ontario Traffic Manual Book 2, 11, and 8 outline the specifications for all types of standards for the signs. Even though sensor technology has rapidly advanced, there are still many

areas that require improvement before level five autonomy can be achieved. Three major challenges related to sensor technology that remain unresolved are: (1) perception in poor weather conditions, (2) perception in changing and unfavorable lighting conditions and (3) human perception of automotive sensor [33].

Furthermore, when it comes to AVs identifying lanes, several limitations have been recognized since most AVs rely on greyscale images. Some of these limitations are as follows:

- Bad weather conditions like mud, rain and snow

- Old road markings not completely obscured even if blacked out

- Bitumen lines used to seal cabling or drainage in the roadway

- Faded indistinct lines on asphalt surfaces

- Slightly faded lines on concrete road surfaces which present poor contrast

- Lane markings not in normal use 
- Discontinuous marking.

As discussed above we can conclude that road markings should always remain visible to the driver and the intelligent vehicle, irrespective of weather conditions. Although the maintenance of road signs and markings are well stipulated, this does not ensure that signs and markings are currently maintained to the level likely to be required by AVs as shown in figure 4 . They rely on road signs and markings to guide them whilst driving. A similar problem is caused by poor maintenance of road signs. The Design Manual classifies dirty signs as 'Category 2' defects, which are deemed to be low priority and can take up to 6 months to be rectified. Road signs are inspected every 12 months, meaning they could spend a significant period in a state that is unreadable by AVs.

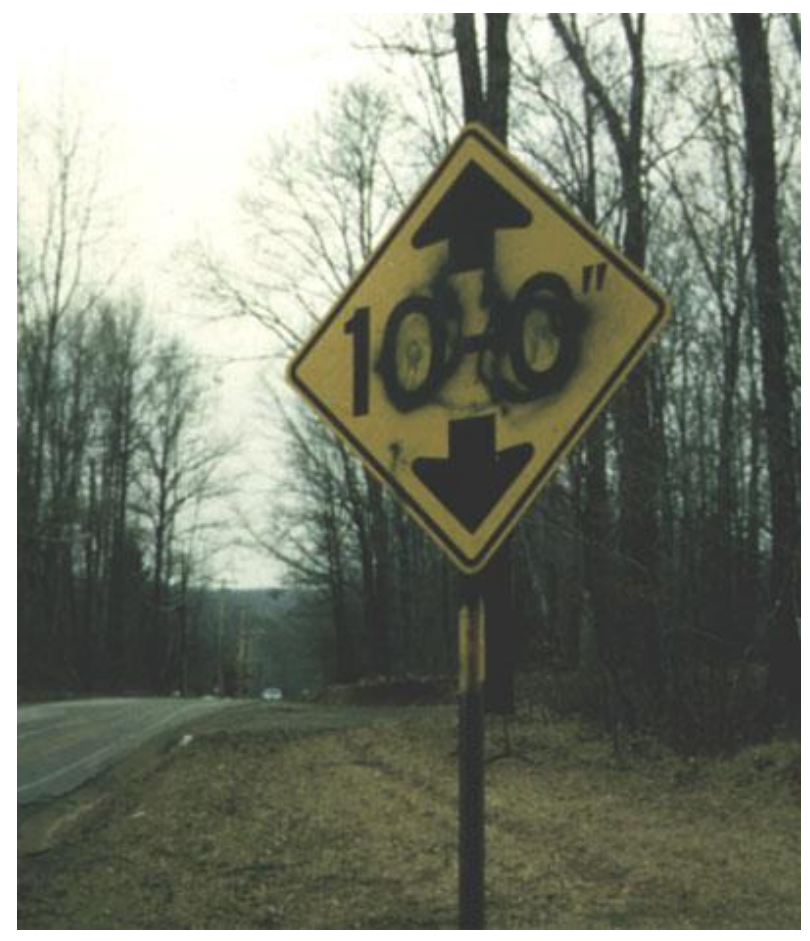

Figure 4: Example of a poorly maintained sign 


\subsection{2 - Future Recommendation}

The initial investigations propose that there is no real need for significant change to the design of road markings or road signs. This is predominately due to the fact that the current standards are well defined, and that AV developers have made mention only to the inadequate state of road markings and road signs, and not their design. Despite this, certain standards should be designed which are same all over the country, it offers uniformity for developers to program their vehicles against. Similarly, any uniformity that can be given to safety critical road signs would be of benefit [34].

Although consideration should be given to uniformity in terms of design, the most important aspect is to ensure lane markings and road signs are maintained at a high standard. This extends to more general road maintenance such as pot holes which may confuse AVs. The current state of road signs and markings should be reviewed to ensure they are meeting the current standards, particularly for road types where AVs are expected to operate first, such as motorways and high-speed dual carriageways. During review, a collection of "worst-case" signs and markings should be catalogued to understand what the minimum standard or sign and marking is, and these could be used by AV developers to understand what their requirements are.

An important opportunity for road maintenance is presented by AVs. They could use their sensors and communications equipment to report in real time any issues with signs, markings and other general road maintenance issues to the authorities. This could be extremely useful data that could shape how the road Infrastructure Requirements for AVs. Network is managed and maintained. To exploit this opportunity, authorities need to work closely with vehicle manufacturers and potentially telecommunications companies to ensure the information can be collected, communicated and utilized. Areas of private land are more difficult to control. AV- 
compatible zones may need to be established. These zones could mark areas that have been checked and certified as suitable for use by AVs. Areas that do not meet these requirements may only be used in manual driving mode only. Issues regarding road markings around junctions will be discussed in the section later.

For further detailed recommendations:

Chapter 2 - section 2.3: Drivers Requirements

In this section, drivers' requirements specify that sign design must take into account driver limitations in detecting signs in the roadway environment, processing the sign information, and selecting an appropriate response. The more a sign meets driver needs, the more likely a driver will detect it, the more likely he or she will be able to read and understand the message, and the more likely he or she is to select the response desired by the traffic practitioner. However, there is no section that discusses AV's requirements and considers the limitations when it comes to determining the appropriate letter size, the selection of font, contrast, retro reflectivity, spacing of sign elements and borders, message layout, and reading time, as well as longitudinal sign spacing and placement in the field that the AV can deal with.

$>$ Chapter 2 - section 2.7 Calculating Letter Height and Symbol Size

Certain criteria need to be set to determine the effectiveness of signs when AVs are introduced. All the signs must be pre-programmed in the AVs to make it easier for the vehicle to respond quickly. In this section number of factors have been considered to ensure that signs are legible at an appropriate distance when it comes to the driver's perspective regarding reading time, decision time, maneuver time, required legibility distance and minimum letter height.

However, all these factors need to be investigated from an AVs perspective. For example, the distance it takes for an $\mathrm{AV}$ to respond to a sign needs to be tested in order to find the best 
location for the sign to be placed. That distance must accommodate both a driver in a human driven vehicle and an $\mathrm{AV}$ and its built-in sensors.

Listed below are summarized key recommendations when it comes to sign design, fabrications and patterns for public roads:

1. Consider ongoing global research into appropriate road markings for AVs.

2. With road markings forming the 'rails of automated steering systems', the procedures for maintenance of road markings may need to be improved and funding increased.

3. With some systems relying on visually detecting and interpreting traffic signs it could be important to ensure that they are maintained to a high standard in terms of cleanliness, clarity, deterioration, non-ambiguous positioning, and obscuration.

For private roads:

4. It may be necessary to work with land owners to ensure unadopted roads are checked and certified for use by CAVs / AVs.

\section{4 - Pedestrian Crossing Treatments}

Crossings and junctions are a key part of the road network. Several studies have been done on pedestrian crossing behavior as it gives insights into traffic lights design, pedestrian safety, roadway layouts design and traffic flow optimization. This study also analyzes the distracted pedestrians' waiting time before crossing the road in three conditions: 1) not distracted, 2) distracted with a smartphone and 3) distracted with a smartphone in the presence of virtual flashing LED lights on the crosswalk as a safety measure[35]. This section discusses the issues associated with connected autonomous vehicles (CAVs) at junctions and crossings, and potential strategies for addressing them. 


\subsection{1 - Current Situation}

The major challenge that autonomous vehicles are facing today is to drive in urban Table 2: Categories of pedestrian's crossings

environments with multimodal traffic. In order to secure the future of autonomous vehicles, it is required that they can communicate with the other road users and understand their intentions. Such intentions play a vital role between the vehicles and the pedestrians, as they are the most vulnerable road users. In order to understand the pedestrian's behavior, we need to look at the various factors such as demographics of the pedestrians, traffic dynamics, environmental conditions, etc. Categories of Pedestrians Crossings are listed in Table 2.

\begin{tabular}{|c|c|}
\hline Controlled Crossings & Uncontrolled Crossings \\
\hline $\begin{array}{l}\text { - Traffic Control Signals } \\
\text { - Intersection Pedestrian Signals } \\
\text { - Mid-block Pedestrian Signals } \\
\text { - Pedestrian Crossovers } \\
\text { - STOP Sign } \\
\text { - YIELD Sign } \\
\text { - School Crossing when a School } \\
\text { crossing guard is supervising }\end{array}$ & $\begin{array}{l}\text { - Mid-block Crossings (in the absence of } \\
\text { traffic control signals, intersection } \\
\text { pedestrian signals or pedestrian } \\
\text { crossover) } \\
\text { - Designated School Crossing (in the } \\
\text { absence of a crossing guard and } \\
\text { without other forms of control such as } \\
\text { traffic control signals, intersection } \\
\text { pedestrian signals, pedestrian } \\
\text { crossover, STOP signs or YIELD } \\
\text { signs) } \\
\text { Marked Crossing (at intersection in the } \\
\text { absence of STOP or YIELD signs) } \\
\text { Roundabouts }\end{array}$ \\
\hline
\end{tabular}

\subsection{2 - Future Recommendations}

Pedestrian crossings are perhaps one of the most challenging everyday aspects of operating CAVs in an urban area. They are not a compliant part of a system (not a mandatory stop e.g. Signal or stop sign) who can be directed and controlled and are expected to exercise free will, which can be experienced as a random and chaotic variable by the automated system. 
Unlike many of the potential obstructions on motorways which are quite rare but still need to be addressed, pedestrians are vulnerable and will be frequently and routinely encountered by urban CAVs yet offer many behavioral and detection challenges. From mischievous teenagers looking for a prank to impress their friends to people with more malevolent intentions, knowing when to stop whilst keeping vehicle occupants secure could present a challenge for CAV operations $[21]$.

Recently emerging C-ITS solutions may offer significant steps forward with the pedestrian detection challenge for controlled crossings, as referenced in a press release by Neavia Technologies [34]:

“...vehicles equipped with V2X technology can automatically receive alerts when pedestrians are crossing or about to cross a road. This represents a significant step forwards for road safety: In many situations, pedestrians are not visible by to car drivers. They can be hidden due to the road configuration, or by other vehicles. They can also be less visible in case of fog, or under poor lighting conditions. In those situations, vehicles' ADAS systems (Advanced Driver Assistance Systems) are less relevant or reacting extremely late."

The main concern for these approaches is their potential for inconsistency, as they are being offered to bolster the vehicle's own performance rather like ADAS does for a human driver. If they are to be relied upon then they need to be designed so that the vehicle's systems place the same level of reliance on the infrastructure support each time a crossing is approached. This mean that both the pedestrian detection and the communication mechanism need to meet agreed minimum performance standards rather than taking the current approach of: "it will help when it can."

Infrastructure adaptation could lower the risks on dedicated crossings. Informal crossing on arbitrary sections of road will still incur risks from sensing limitations, but these could be 
mitigated by improving public understanding and updating the Highway Code and laws in respect of these technological limitations In the same way that it is accepted that you do not have a right to roam on railways, rather it is a form of trespass, some consideration to obstructing traffic flow by being in the road may have to be given on the grounds of both safety and disruption.

Two forms of crossing are considered: controlled crossings and uncontrolled crossings which can take place almost anywhere.

$>$ Uncontrolled crossings

Uncontrolled crossings could present a challenge to CAVs. One issue, particularly from CAVs point of view, is understanding who has the right of way. Vehicles are required to stop when pedestrians step on to the crosswalk. However, pedestrians should wait for an approaching vehicle to slow significantly (to make sure it can and does stop) before crossing. If these rules were applied literally by all parties, then either pedestrians would never be able to cross on busy roads or there would be a stalemate whilst one waits for the other. It is left to the judgement of the pedestrian (who may be a child with limited ability to judge) as to whether a vehicle has enough time and distance to comfortably stop without hitting them on the crossing.

The technically simplest approach to unsignalized crosswalks may be to replace them with signaled ones which are far more deterministic and do more to discourage people just stepping out or even running out on to the crossing. However, it may not be practical or cost effective to remove or upgrade them. One question is how to discourage pedestrians stepping out in front of a CAV at the wrong moment. It should be borne in mind that any CAV pedestrian sensing system no matter how good may fail at some point, so prevention is better than cure in that pedestrians need to wait for the vehicle to demonstrate that it is going to stop for them, or in sufficient and for sufficient time for them to cross. This could be achieved via an external visual/audible human machine 
interface on the vehicle, or via a similar system which is post mounted on the crossing. There would be a need for some conformance in the approach such that pedestrian become accustomed to one clear message rather than a range of solutions (for example different vehicles using different graphics / sounds).

For this reason, the crossing infrastructure (post mounted) approach has some appeal, but it adds the additional complexity of requiring a failsafe mechanism for cars which do not announce themselves to the crossing. This would likely employ a similar mechanism to signaled junctions where the vehicle must always know when it is encountering a crossing and expect a handshake before continuing though at full speed. Further confusion may result from the mixture of legacy vehicles with CAVs. Just because every approaching CAV has announced it will stop, does not mean a manually driven vehicle's driver has noticed a pedestrian is on the crossing. A proceed to cross with caution message may help with this as a reminder to crossers that they should make the final visual check themselves. More thought may need to be given to people being led by guide dogs.

The other part of the equation is pedestrian detection. This could be done from post mounted infrastructure, or from the approaching vehicle. The issue with a vehicle-based strategy alone is that it may fail to detect pedestrians under some conditions, not least due to the limited field of view from the vehicle. A technically superior solution would be to do the detection from the infrastructure with vehicle-based detection also used as a final resort in case a pedestrian runs out onto the crossing. Time-of-flight and infrared camera pedestrian detecting sensors are being developed for infrastructure mounting and these offer the reliably and robustness to weather and light conditions and well as field of view when appropriately mounted. Also, infrastructure-based vehicle detection is already common practice. This makes having the crossing itself as the one 
source of the truth to perform the crossing arbitration seem an attractive option for an assured system [33].

\section{Controlled Crossing}

In this case there is a need for AV to be sure of the signal status. There is a possibility that pedestrians may not wait for the correct signal phase and may cross early or late and run out in order to try to make it in time before cars pull away. Electric Vehicles will not have the running engine restarting as a clear indicator that vehicles are starting to move off. It is suggested that the flashing amber phase can be removed entirely since with pedestrian detection the red phase can be extended longer if there is a requirement. Having the ambiguity of the flashing amber phase only provides opportunity for problems leading to the vehicle needing to detect itself if there are any stragglers on the crossing which may be prone to error. Different vehicle would potentially have different implementations of this, and it could be better left to the infrastructure with wider and dedicated sensing capabilities to make the final judgement to proceed if clear.

\section{5 - Design of Parking for CAVs}

The idea of 'autonomous valet parking' has been discussed for many years, and several car companies have demonstrated systems which show a CAV capable of searching for, detecting and maneuvering into a parking space with no human intervention. This creates exciting opportunities both for the user and for the infrastructure provider. Firstly, for the user, this would enable a driver to park somewhere close to the entrance of a car park in a designated vehicle drop off area and continue directly to their destination without the time and stress of parking a car. The car could be subsequently summoned to a collection area. 


\subsection{1 - Current Situation}

In theory, when empty CAVs could park themselves very efficiently, without the need for human occupants to open the doors. This alone could enable $20 \%$ more spaces to be provided within a car park [34]. Taking it one step further, CAVs could block each other in and let each other out when necessary. A study by Audi suggested 2.5 times the number of vehicles could fit into a car park using this method compared to human-controlled vehicles.

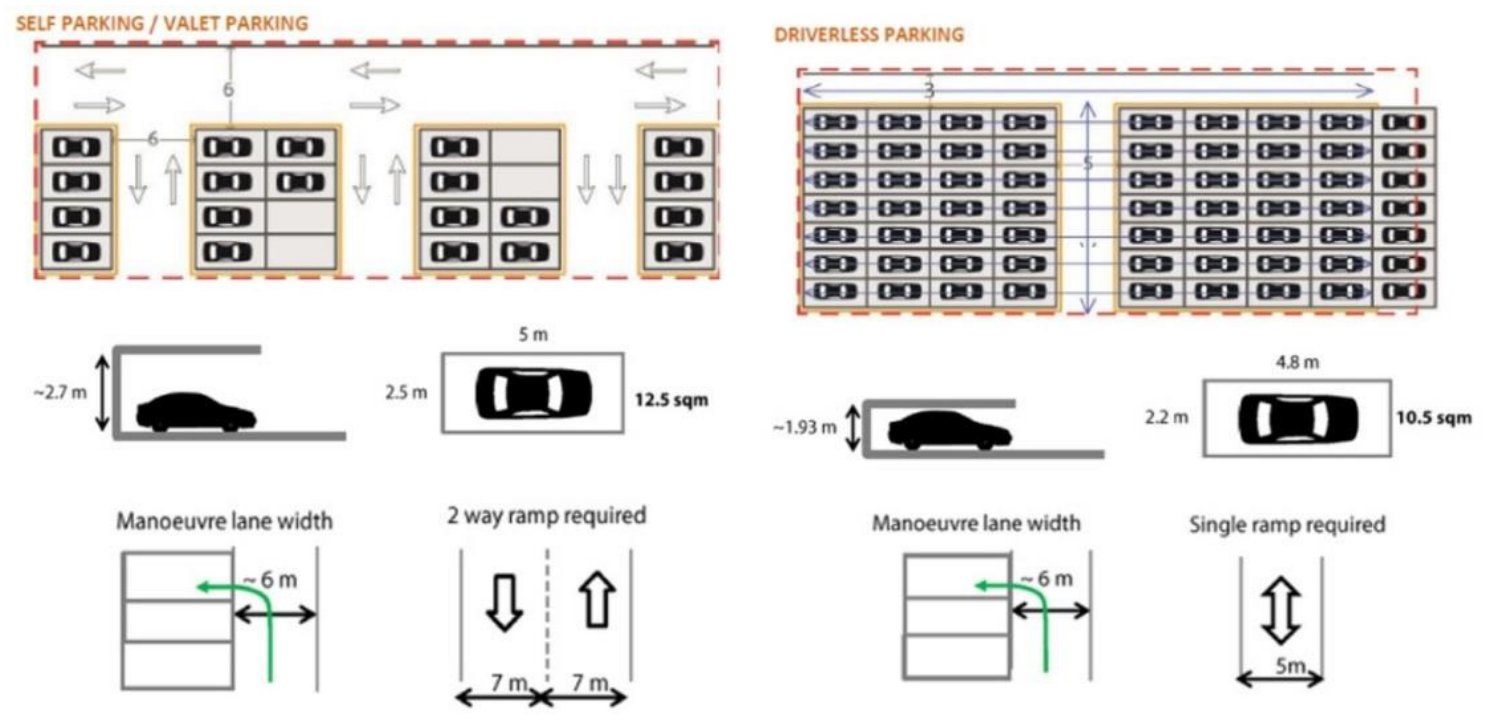

Figure 5 Conventional parking layout (left) vs possible CAV parking layout (right) [36]

Figure 6 has been captured from a video which simulates how CAVs could park themselves in a highly efficient manner [37]. The idea of the layout shown is that each vehicle can be blocked in by up to two other vehicles. If that vehicle needs to exit, the other two vehicles will move out of the way to allow passage.

Enabling vehicles to maneuver as directed by the car parking system could be challenging. Some form of remote-control access will need to be granted to the car park operator. Having vehicles that are capable of being controlled in this manner (which includes ignition, throttle, brakes, and steering), could expose the CAV to cyber security threats. Safe guards would also be needed if a vehicle does not respond, and how to retrieve any vehicles that may be blocked. 


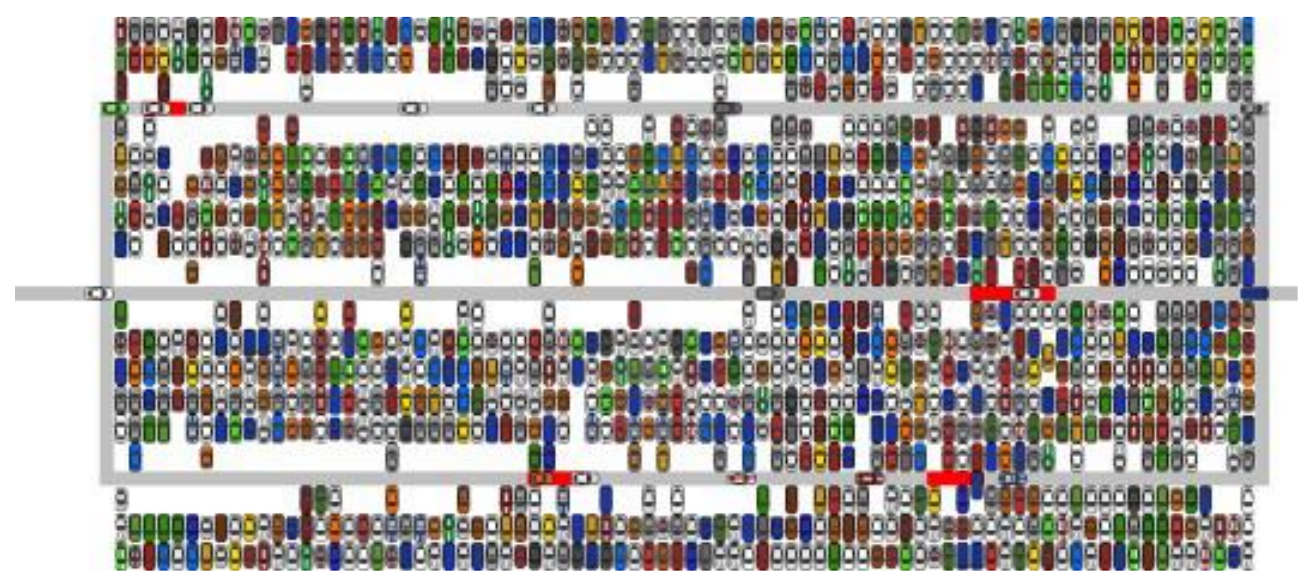

Figure 6 Potential layout of CAV carpark, achieving high parking density[36]

In addition, since no driver may be present, any car park operator intending on allowing CAVs with no occupants into their car park would need to establish an automatic electronic payment method. This could be done via number plate recognition, an electronic tag, or V2I communication.

\subsection{2 - Future Recommendations}

Regulations relating to CAV parking are advancing quickly. ISO/DIS 16787, "Intelligent Transport Systems - Assisted Parking System (APS) - Performance requirements and test procedures”, has been drafted. The standard “...establishes minimum functionality requirements that the driver can expect of an APS, such as the detection of suitable parking spaces, calculation of trajectories, and lateral control of the vehicle...". This standard also sets minimum requirements for failure indication as well as performance test procedures. It includes rules for the general information strategy but does not restrict the information type or display system." Referring to this ISO can aid authorities and car park operators in better understanding what is required for a car park for CAVs. 
Infrastructure Requirements:

One challenge with regards to CAVs in car parks relates to consistency. As many car parks are privately operated, they do not always use conventional road markings. They often incorporate one-way systems and other traffic controls, and signage and markings can be inconsistent from one car park to the next. CAVs may struggle to navigate these environments, and this issue also is relevant to service stations. It may be advantageous in the longer term to agree international standards for CAV compliant car park signage and markings. A short-term measure would be for CAV developers to map individual car parks digitally to ensure their systems work in that car park.

To start achieving some of the benefits of CAVs within car parks, areas of car parks could be designated as CAV only. This area would have clear and compliant line markings and be free from pedestrians and human-operated vehicles. Operators could be incentivized by the ability to fit more vehicles into an area, although uptake initially could be low as not many vehicles might have the necessary technology in the early years - a classic chicken and egg problem.

There might be ways to address this problem in the early years. A company that owns a fleet of vehicles, and would benefit from more efficient parking of them, could introduce vehicles with the self-parking technology or an organization which provides company cars for staff could think about using cars with the technology, and designating areas of the company car park for its use.

A future vision for car park design can be seen in a drawing published by US architect firm Arrow street, as shown in figure 7 below. The top level of the carpark is for use by CAVs (since it is the furthest away), with the remaining levels still used for conventional parking. 


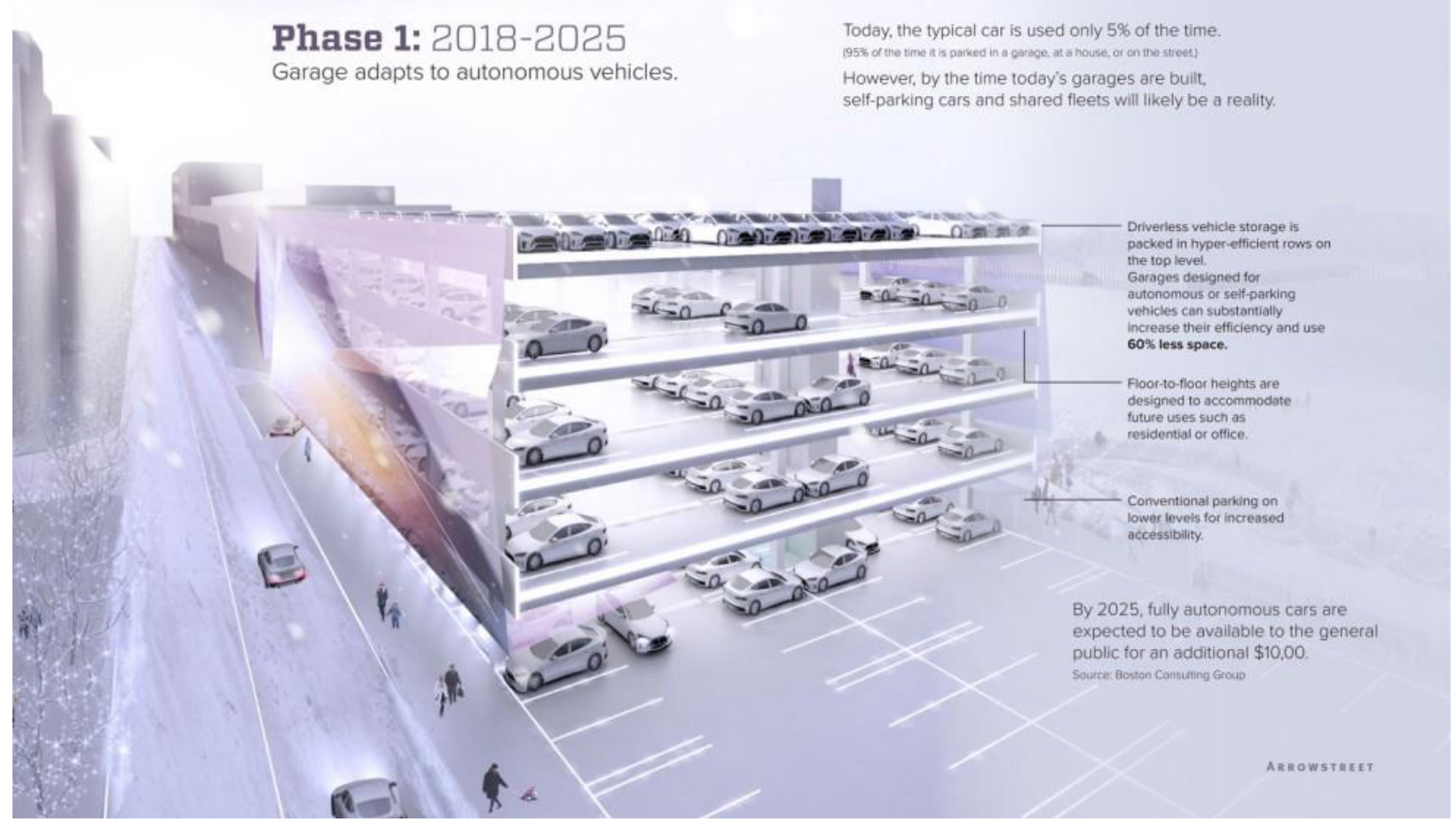

Figure 7 Parking Infrastructure Phase 1 [38]

For compliment CAV-compliant parking areas, valet pick-up/drop-off areas should be considered. This is a designated area where people can drop-off and collect their CAVs. They must be designed with safety in mind and with enough capacity to allow for peak use. It may be that a small area is required initially which can expanded in the future as uptake of CAVs increases. Figure 9 below shows an example of a valet parking area and how a charging system may work within a carpark. A small number of electric charging spaces are provided, and owners can move their cars in and out as required. 


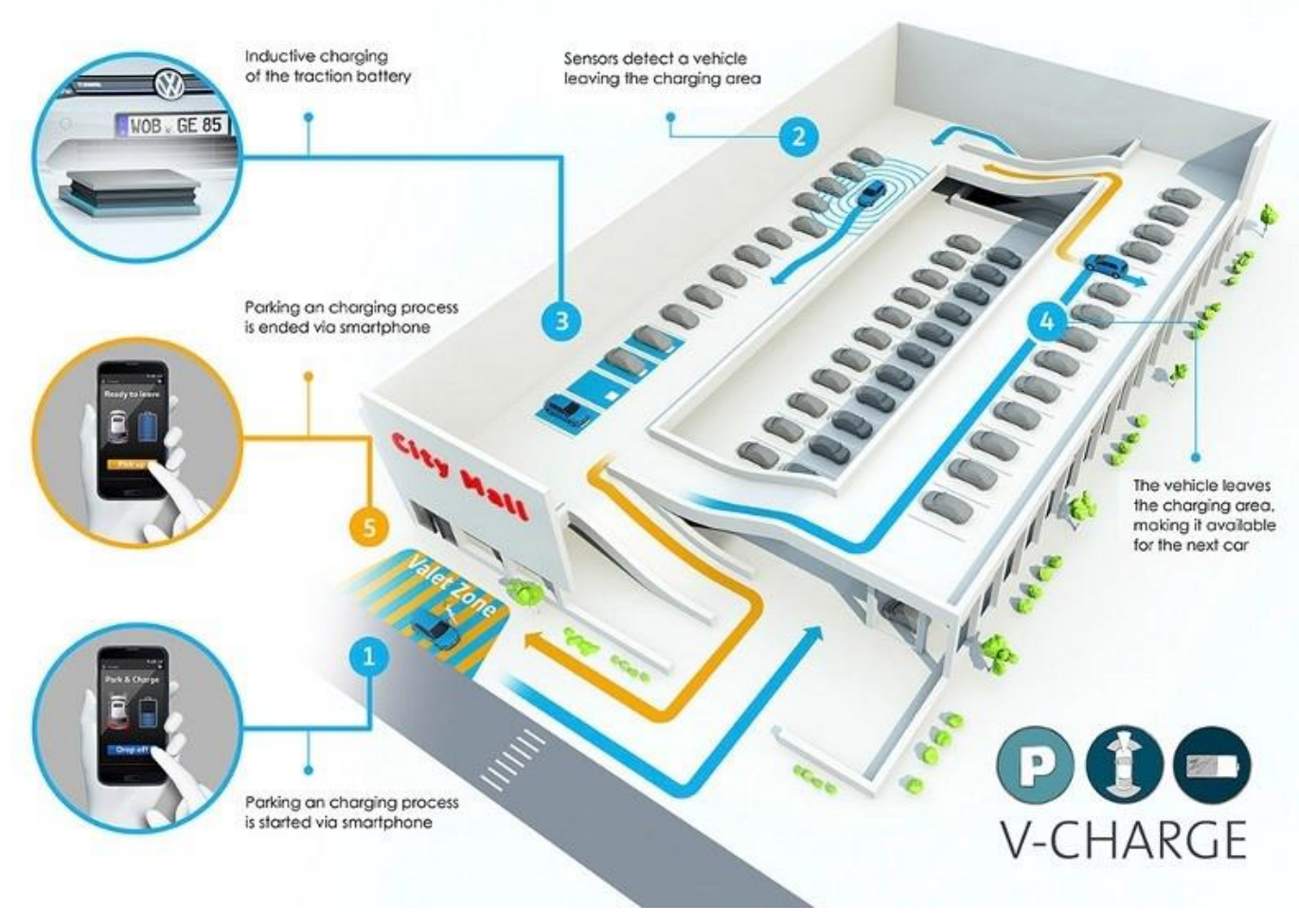

Figure 8 Parking Infrastructure[34]

At a government level, a guidance document for carpark operators could be produced, providing a list of recommended processes to follow, and their associated benefits. The guide could give suggested layouts/designs for CAV-compatible carparks and infrastructure that could be fitted to enable more advanced automated parking solutions. It could discuss the potential benefits of fitting communications equipment to enable infrastructure to vehicle communications, data collection systems such as car park monitoring sensors which keep track of which spaces are available in real-time, or automatic electronic payment systems. Close collaboration would be needed with the vehicle technology developers in producing such a document.

Establishing a CAV parking test area in the Canada would allow developers to begin testing their CAVs in different car park layouts and scenarios. This could accelerate the development of CAV valet parking by allowing operators and developers to work together, as well as allowing the 
government and car park operators to observe progress in this technological field. Some key findings from this section could be:

1- Consider creation of a CAV parking test areas in the Canada for developers to use for testing.

2- Consider options for allowing CAVs to pass oncoming vehicles where on street parking limits flow to one direction. Options might include removal of parking or conversion of the street to one-way operation.

3- When planning future land use consider that, over time, parking demand could decrease, and space currently used for parking could be available for other uses.

4- Architects and planners could adopt a flexible approach to car park design and planning, acknowledging the potential for less demand in future decades. 


\section{4 - Simulation based Evaluation: Case Study of Downtown Toronto}

In this section in order to systematically evaluate the effect of the key changes proposed and to explore several scenarios, a specific calibrated microscopic traffic simulation model in VISSIM was used to estimate the effect of AVs on relevant traffic performance measures. The employed traffic model has been calibrated for real downtown Toronto network with 25 signalized intersection. Further the calibration on car following model (Wiedemann 99) were performed for Automated Vehicles.

\section{Description of Study Area}

For the area of study as shown in Figure.10 below we focused on the core of the financial district in downtown Toronto highlighting University Ave. Corridor. University Avenue is a major north-south road in Downtown Toronto, Ontario, Canada. Beginning at Front Street West in the south, the thoroughfare heads north to end at College Street just south of Queen's Park. Many of Toronto's most important institutions are located along the eight-lane wide street such as Osgoode Hall and other legal institutions, the Four Seasons Centre, major hospitals conducting research and teaching, and landmark office buildings for the commercial sector, notably major financial and insurance industry firms. Due to the existence for these important institutions the University avenue corridor is highly congested. 


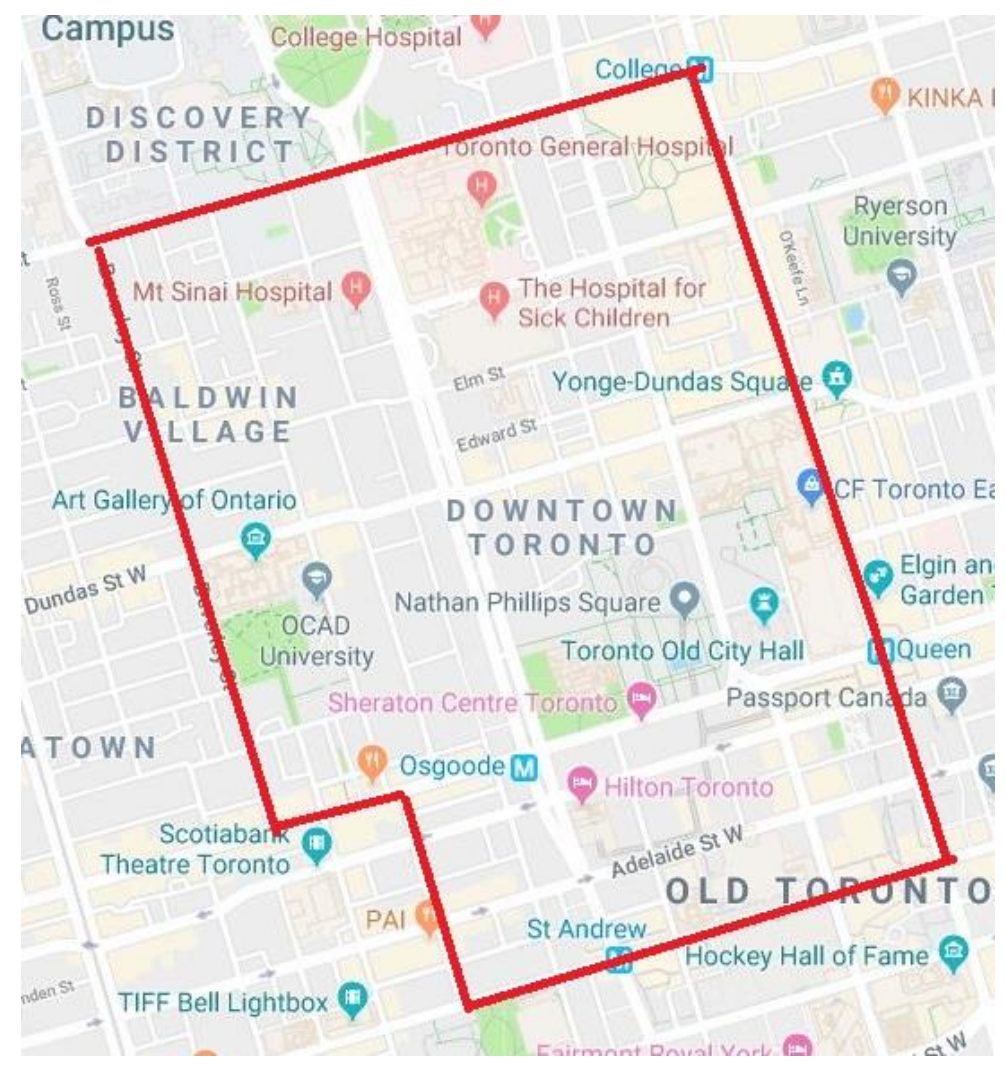

Figure 9 Area of Study

The primary focus in this research will be on the following intersection along University Avenue:

1. College St at University Ave

2. Gerrard St at University Ave

3. Elm St at University Ave

4. Dundas St at University Ave

5. Queen St at University Ave

6. Richmond St at University Ave

7. Adelaide St at University Ave

8. King St at University Ave 
The University Ave is considered one of the most congested corridors in the AM peak. In order to get a better understanding of the current scenario simulation was carried out using VISSIM with current volume and signal timings obtained from City of Toronto. Various scenarios were built upon the current situation exploring the effect of AV's with current volumes and with growth rate of $10 \%$ and $20 \%$ to predict the future impacts of AV's on the current network.

\section{1 - Methodology for Scenarios}

By using PTV VISSIM software and obtaining the data from City of Toronto a traffic network was created to replicate downtown Toronto's network from lane configurations, signal timings and signal phasings. The current scenarios were evaluated to determine the effect of introducing $\mathrm{AVs}$ through different market penetration rates and volumes to our current network.

Table 3 below shows the characteristics of the different scenarios simulated on PTV VISSIM with regards to volumes chosen and varying market penetration rates. Furthermore, Figure 11 represents a general flow showing the major steps that were used to implement each and every scenario. The reason we chose $30 \%, 50 \%$ and $70 \%$ was to look at having low, medium and high MPR scenarios. One of the main benefits of AVs is that they can drive closer to each other and they require lower reaction time. This reduction in safe distance and reaction time requirements, results in higher capacity of the road and significant improvement. However, when you have low MPR (30\%) you have AVs mostly following HDVs, so having low reaction time or shorter safe distance doesn't do much because $70 \%$ of the vehicles driving at regular stop distance and reaction time. When it comes to 50\% it may improve a little but now you have $50 / 50$ which in fact may even cause conflict but it is when it gets to $70 \%$ that you get to see improvement because most of the vehicles are AVs as such you start to see the benefit of short distance and lower reaction time [39]. 
Table 3: Scenarios Overview

\begin{tabular}{|c|c|c|}
\hline Scenarios & Volumes & MPR's \\
\hline Scenario 1 & Base Volume & $0 \%, 30 \%, 50 \% \& 70 \%$ \\
\hline Scenario 2 & $10 \%$ Growth in Volume & $30 \%, 50 \%, \& 70 \%$ \\
\hline Scenario 3 & $20 \%$ Growth in Volume & $30 \%, 50 \%, \& 70 \%$ \\
\hline Scenario 4 & $20 \%$ Growth in Volume & $30 \%, 50 \%, \& 70 \%$ \\
\hline Scenario 5 & $20 \%$ Growth in volume & $30 \%, 50 \%, \& 70 \%$ \\
\hline
\end{tabular}




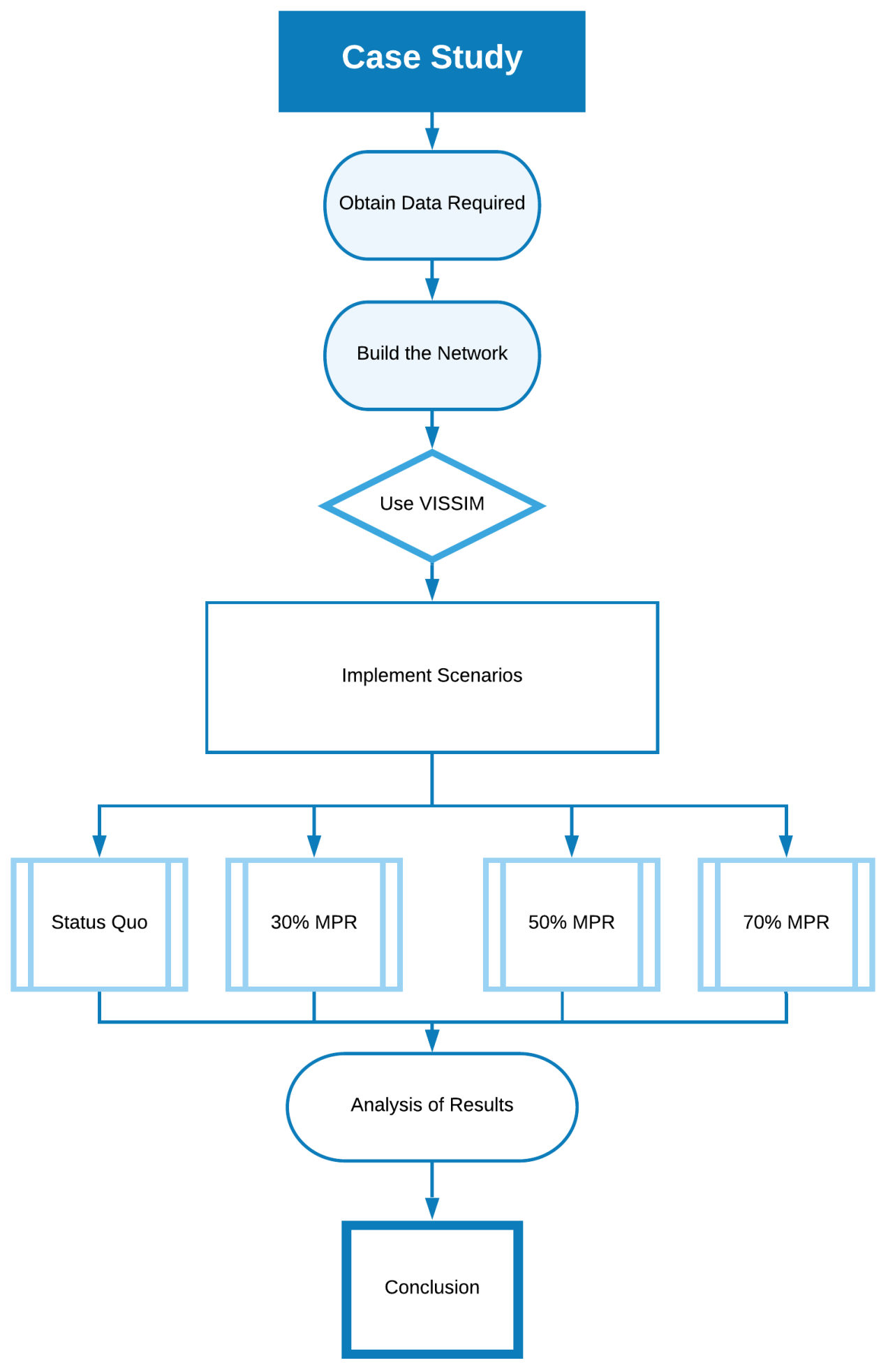

Figure 10 Case Study 
Scenario 1: In this scenario, the simulation was carried out for $100 \%$ Human-driven vehicles (HDV) using the base volume. This scenario is considered a reference line for comparing the future scenarios with varying market penetration rates of $\mathrm{AV}$ as described in the sub scenarios (1-a, 1-b,1-c) without changing volumes or any of the signals attributes.

1-a: Using the base volume we replaced $30 \%$ of the current traffic volumes with Automated Vehicles (30\% AV's \& 70\% HDV's).

1-b: Using the base volume we replaced $50 \%$ of the current traffic volumes with Automated Vehicles (50\% AV's \& 50\% HDV's).

1-c: Using the base volume we replaced $70 \%$ of the current traffic volumes with Automated Vehicles (70\% AV's \& 30\% HDV's).

For Scenario $2 \& 3$ we increased the growth rate to show the effects of AV's in the future since presence of AVs on the road would not happen instantly. Therefore, we wanted to highlight different MPRs at different growth rates and analyze their effects.

Scenario 2: In this scenario, the simulation was carried out for $100 \%$ Human-driven vehicles (HDV) using a $10 \%$ growth rate to the base volume to predict future conditions in the upcoming years. This scenario is considered a reference line for comparing the future scenarios with varying market penetration rates of $\mathrm{AV}$ as described in the sub scenarios (1-a, 1-b,1-c).

1-a: Using the $10 \%$ growth volume we replaced $30 \%$ of the traffic volumes with Automated Vehicles (30\% AV's \& 70\% HDV's) [38].

1-b: Using the $10 \%$ growth volume we replaced $50 \%$ of the traffic volumes with Automated Vehicles (50\% AV's \& 50\% HDV's).

1-c: Using the $10 \%$ growth volume we replaced $70 \%$ of the traffic volumes with Automated Vehicles (70\% AV's \& 30\% HDV's). 
Scenario 3: In this scenario, the simulation was carried out for $100 \%$ Human-driven vehicles (HDV) using a 20\% growth rate to the base volume to predict future conditions in the upcoming years. This scenario is considered a reference line for comparing the future scenarios with varying market penetration rates of $A V$ as described in the sub scenarios (1-a, 1-b,1-c).

1-a: Using the $20 \%$ growth volume we replaced $30 \%$ of the traffic volumes with Automated Vehicles (30\% AV's \& 70\% HDV's).

l-b: Using the $20 \%$ growth volume we replaced $50 \%$ of the traffic volumes with Automated Vehicles (50\% AV's \& 50\% HDV's).

1-c: Using the $20 \%$ growth volume we replaced $70 \%$ of the traffic volumes with Automated Vehicles (70\% AV's \& 30\% HDV's).

For Scenarios 4 and 5 we focused on implementing some of the recommendations that can be simulated for a $20 \%$ growth rate in volume, since it represents the worst case among base cases, $10 \%$ growth \& $20 \%$ growth. These scenarios were developed to investigate the effect of implementing some suggested recommendations on one of the most congested intersection in our area of study i.e. Dundas St at University Avenue.

Scenario 4: In this scenario, the simulation was carried out for the $20 \%$ growth rate to the base volume since it represents the worst case among base, $10 \%$ growth $\& 20 \%$ growth. This scenario was implemented to foresee the effect of change in design speed from $85^{\text {th }}$ percentile to $90^{\text {th }}$ percentile speed with varying market penetration rates of AV.

Scenario 5: In this scenario, the simulation was carried out for the $20 \%$ growth rate to the base volume since it represents the worst case among base, $10 \%$ growth $\& 20 \%$ growth. This scenario was implemented to explore the effect of change in cycle length of the adjacent intersection to Dundas St and University Ave with varying market penetration rates of AV. 


\section{2 - Analysis and results}

\subsubsection{Scenario 1 analysis and results}

To analyze this scenario, we evaluated 2 parameters that determine the how the intersection is operating. First parameter is the maximum queue length as shown in Figure 11 and 12.

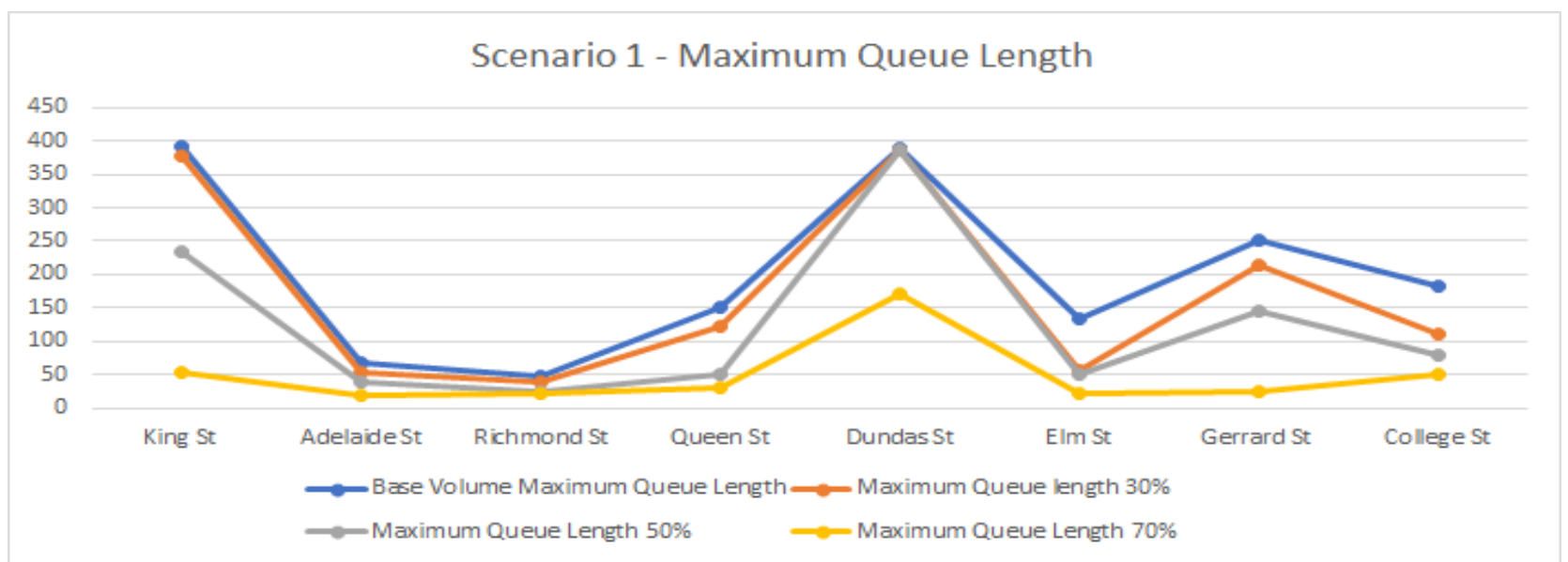

Figure 11 Scenario 1 Maximum Queue Length

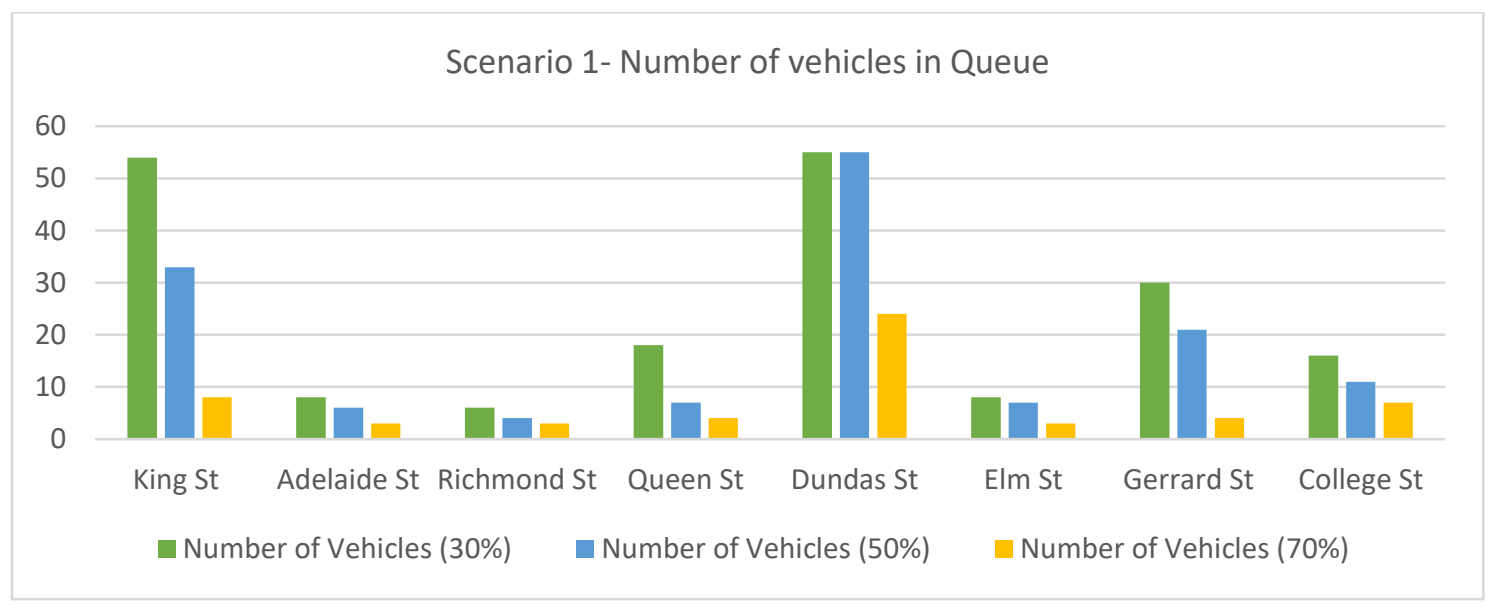

Figure 12 Scenario 1 Number of Vehicles in Queue

In Figure 12, the introduction of $30 \%$ AVs to our network didn't show any significant improvement when it came to maximum queue length. Furthermore, with the increase of market 
penetration up to $50 \%$ we have seen some reduction in the maximum queue length at some intersection, the most evident one is Gerrard St. However, the reductions were insignificant when it came to other intersections due to mixed traffic conditions and the geometry of intersections. Finally, as we can see from the yellow line above representing the $70 \%$ market penetration rates of the AV's had the most significant reduction on the maximum queue length for all the intersections in comparison with $30 \% \& 50 \%$ market penetration rates because of the reduction in human driven vehicles which will allow AVs to operate almost near to their full potential when it comes to reduced headways and stand still distances along with perception reaction time.

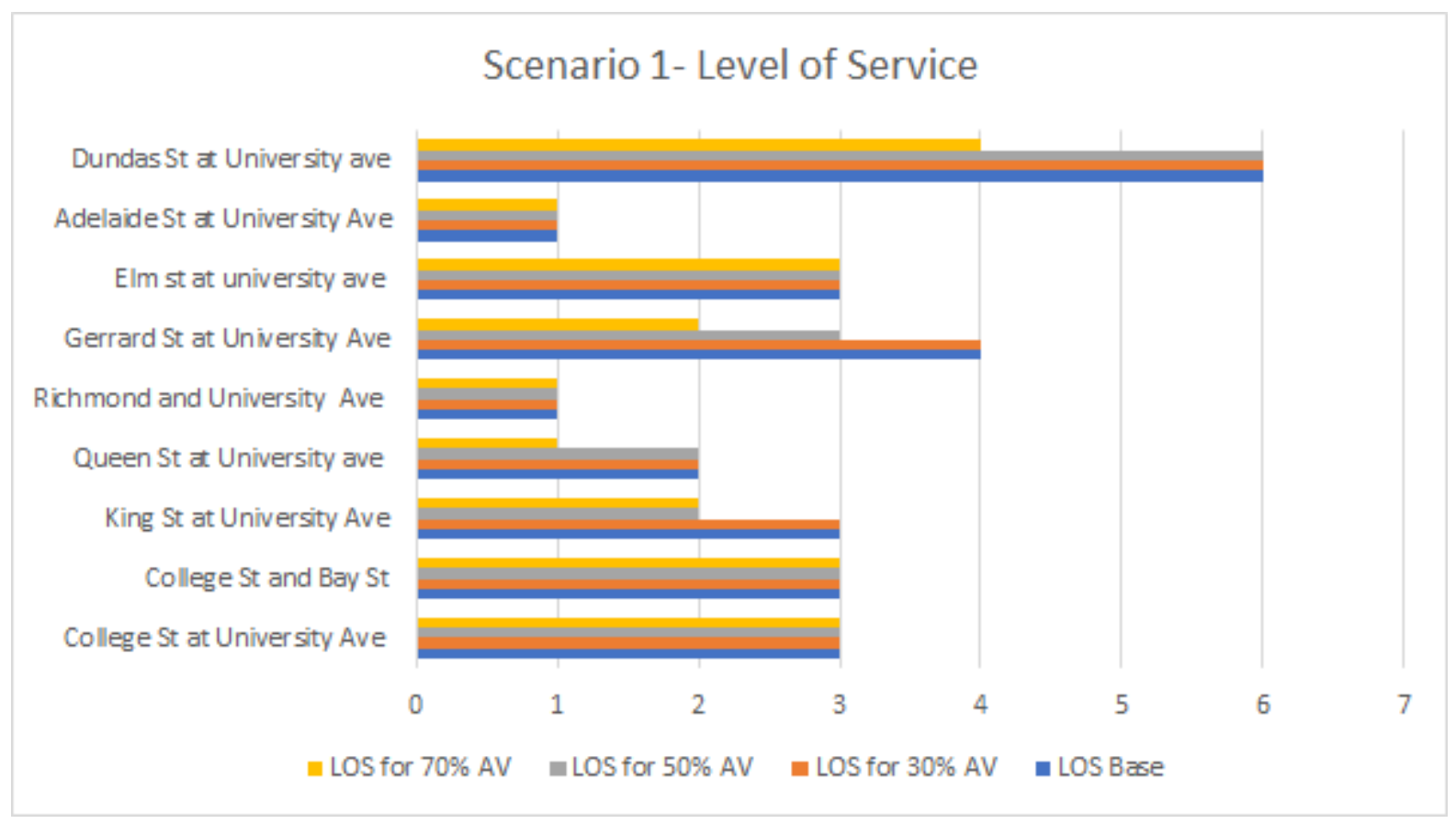

Figure 13 Scenario 1 Level of Service

Level of Service for an intersection varies from $A$ to $F(A=1$ to $F=6)$ depending upon the delay. Since the level of service is represented by range of delays and for our base, $30 \%$ and $50 \%$ scenarios there were no significant improvements in the level of service. Moving on to the $70 \%$ scenario is where the level of service decreased this may be because under $70 \%$ scenario vehicles move closer to each other so roads have higher capacity as such intersections are able to allow 
more vehicles go through them so this may be the one reason that reduces delay at the following intersections: Dundas St., Gerrard St. \& Queen St.

In conclusion, if AV's were to be introduced at our current base volume status at low market penetration rates less than $30 \%$ very low impacts will be evident to our network. However, when we cross $30 \%$ Market penetration rates things begin to improve evidently. when there is a low MPR (30\%) you have AVs mostly following HDVs so having low reaction time or shorter safe distance would not affect as much because $70 \%$ of the vehicles driving are at regular stop distance and reaction time. When it comes to $50 \%$ it may improve a little but now you have 50/50 which in fact may even cause more conflict but it is when it gets to $70 \%$ that you get to see improvement because most of the vehicles are AVs as such you start to see the benefit of short distance and lower reaction time.

\subsubsection{Scenario 2 analysis and results}

To analyze this scenario, we investigated 2 key parameters that determine the how the intersection is operating with the growth rate of $10 \%$ to predict future conditions in the upcoming years. First parameter is the maximum queue length as shown in Figure 15.

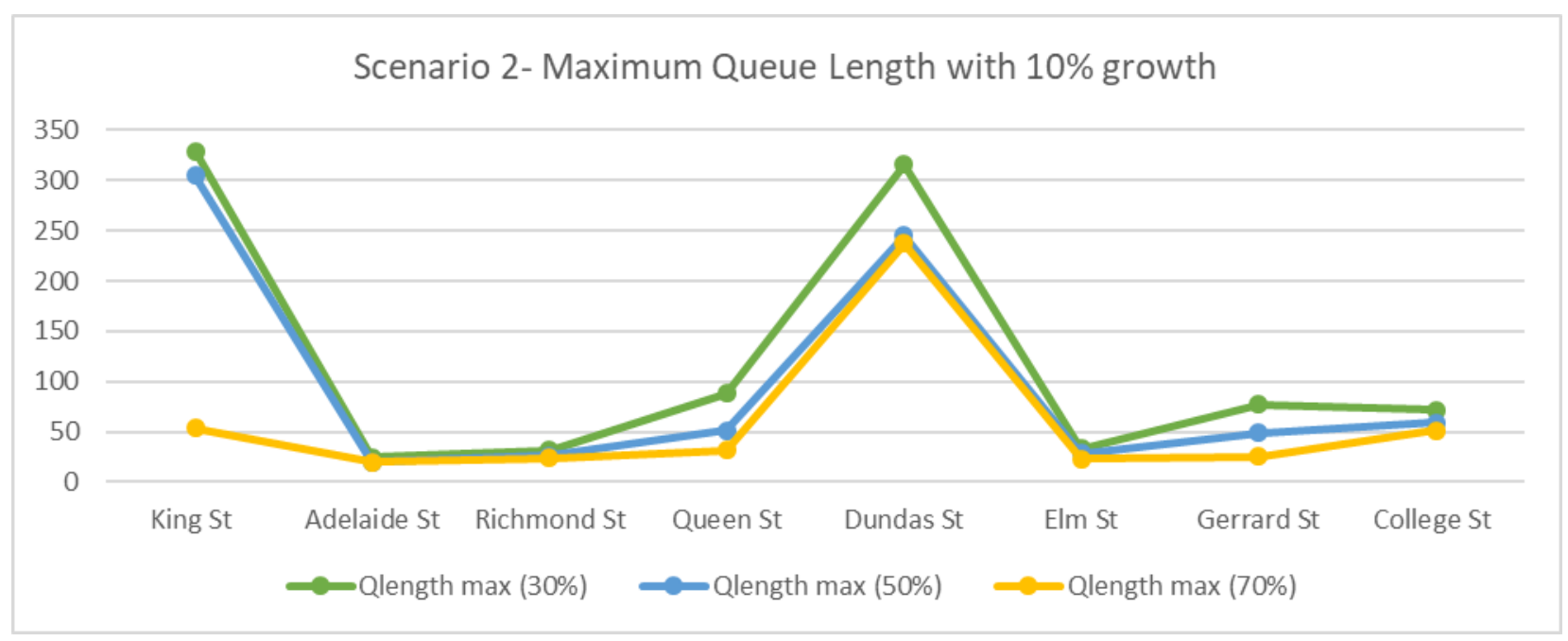

Figure 14 Scenario 2 Maximum Queue Length 
In Figure 15 with the increase in the growth rate of the traffic volume, there is a significant decrease in the performance of the network. There is an increase in the queue length on some of the intersection which shows that once the traffic volume increases in the future the queue length on the intersections will increase due to the extra traffic regardless of the vehicle being a human driven vehicle (HDV) or an AV. Therefore, Connected Autonomous Vehicles (CAV) must be introduced to reduce the queue length by having the ability to communicate with other vehicles and the infrastructure to change routes when facing a congested intersection. However, that being stated, some improvements occurred to the intersections with higher MPR's but not as expected.

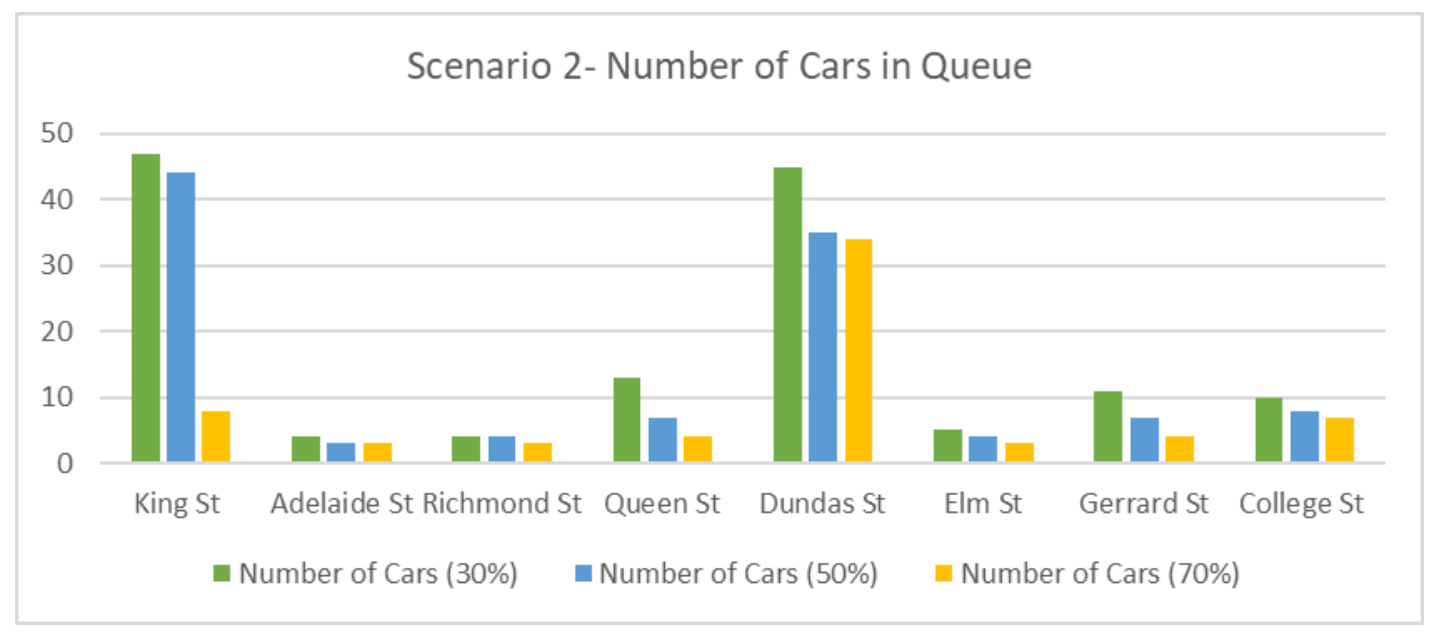

Figure 15 Scenario 2 Number of Vehicles in Queue

The figre 15 above shows the number of vehicles in queue for all the intersection over the varying market penetration rates. It can be seen easily that as the number of AVs in the system are increasing there is a significant change in the number of cars in queue. But after a certain point this change is not much evident because the Automated Vehicles without connectivity won't provide significant improvement in the network.

In conclusion for do-nothing scenario, if only $\mathrm{AVs}$ are to be introduced at growth volumes after a certain limit beyond the intersections capacity there won't be much changes in terms of LOS of the intersections because aggressive AVs can improve the system till a certain point 
because of reduction in standstill distance and headway distance but as the market penetration goes up to there is need of Connected Automated Vehicles and for that we need V2I, V2X and many other infrastructure updates.

\subsubsection{Scenario 3 analysis and results}

To analyze this scenario, we investigated 2 key parameters that determine the how the intersection is operating with the growth rate of $20 \%$ to predict future conditions in the upcoming years. First parameter is the maximum queue length as shown in Figure 16.

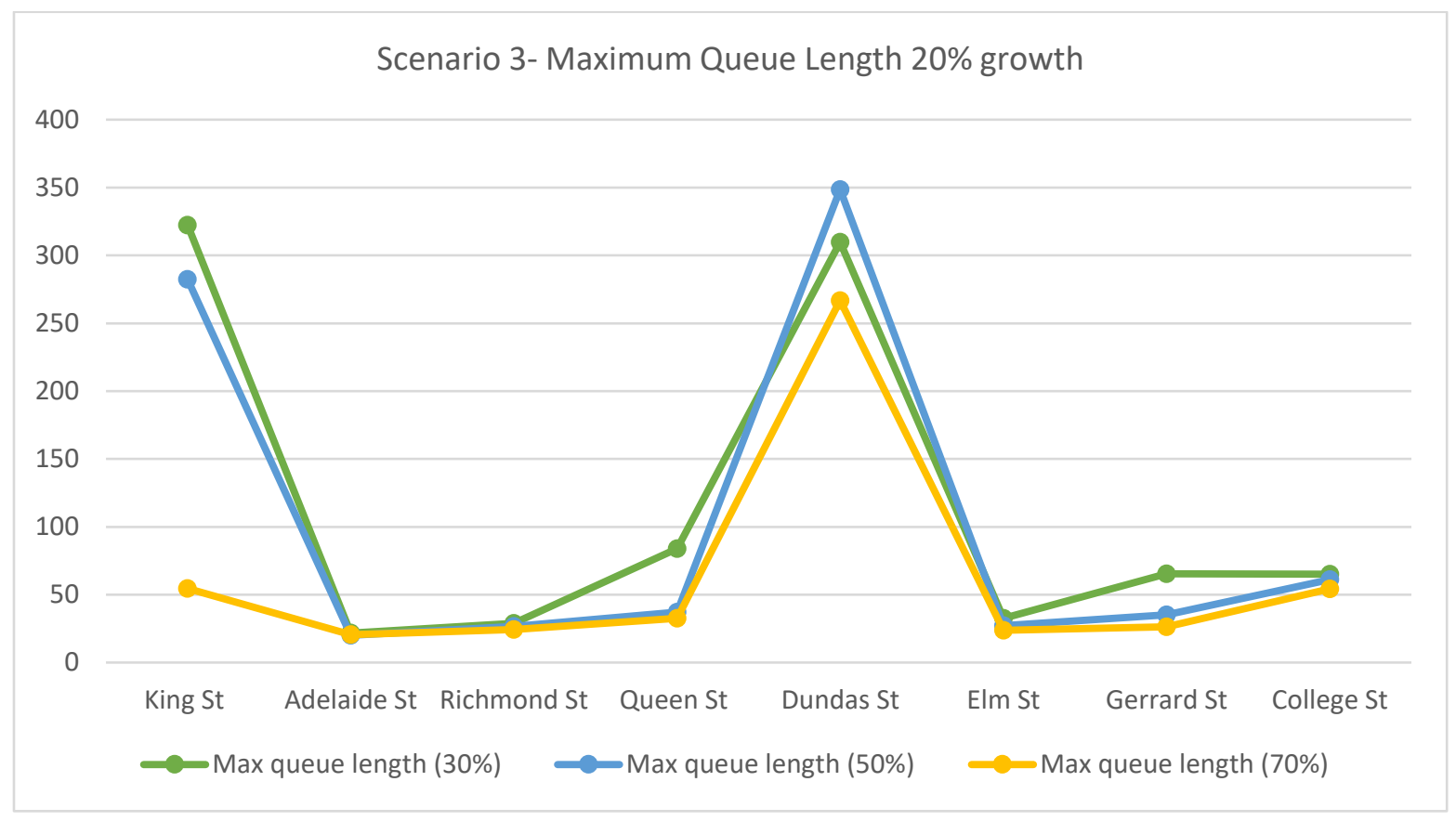

Figure 16 Scenario 3 Maximum Queue Length

As it can be clearly seen in the figure 16 with the $20 \%$ growth rate there is a change in the result the 50\% Market penetration rate shows the maximum queue length at Dundas St and University Ave. This might be because of one reason that with $20 \%$ increase the effect of standstill distance, headway distance, acceleration all has reached to the saturation and there is a need for these AV's to connect to each other (including the infrastructure) which will not only improve the maximum 
queue length but will definitely reduce the other parameters such as travel time, level of service, vehicle delay. The figure 17 below shows the number of vehicles in the queue at varying market penetration rates. It can be easily observed that at Dundas St the number of cars for $50 \%$ market penetration rate was highest because at 50 is where we have the highest number of mixed traffic and also, the Dundas St has a higher volume of demand so the effect here was more obvious.

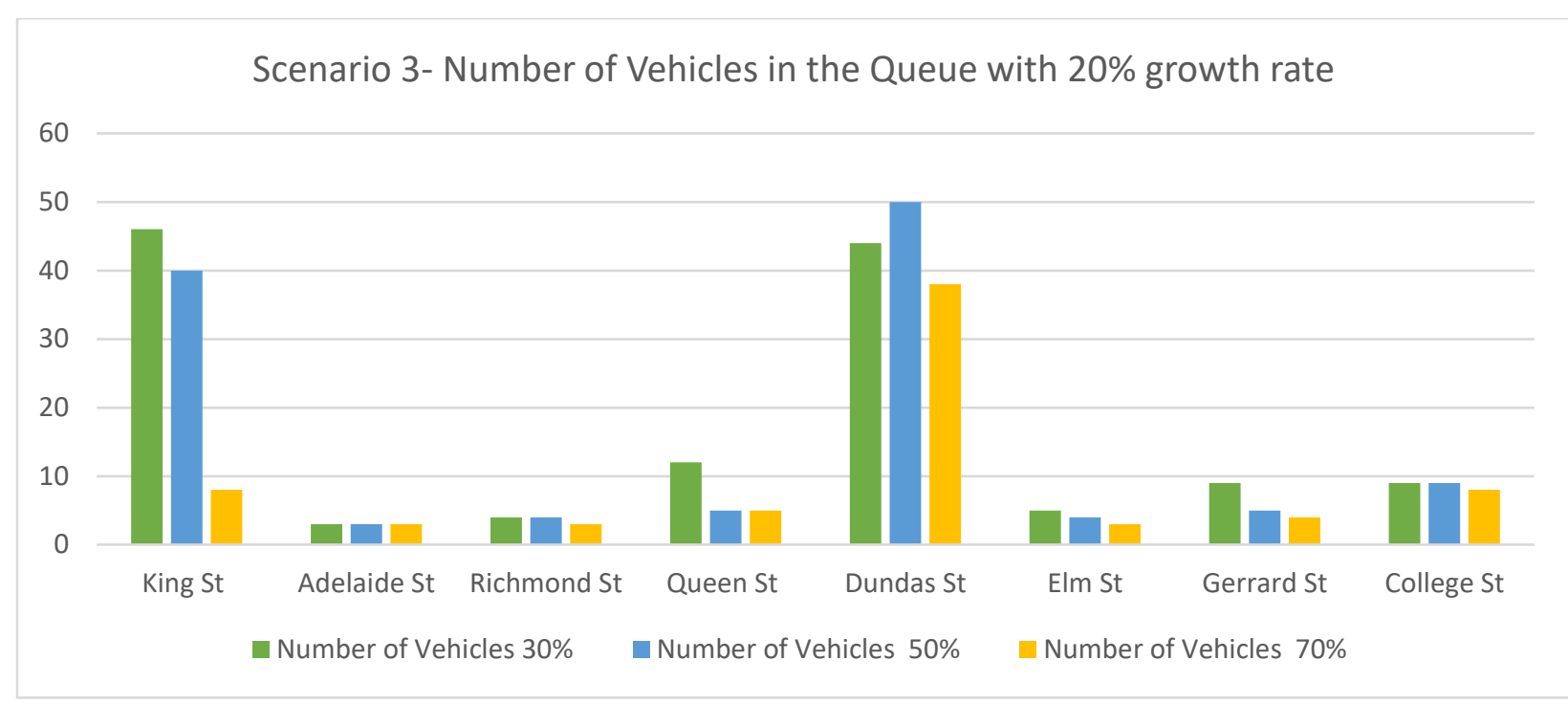

Figure 17 Scenario 3 Number of Vehicles in Queue

\subsubsection{Scenario 4 analysis and results}

To analyze this scenario, we investigated one of the worst intersections in the University Ave. corridor which is Dundas St and University Ave based on the key parameters that determine how the intersection is operating at the growth rate of $20 \%$. Figure 19 below shows the satellite view of Dundas St at University Ave intersection. 


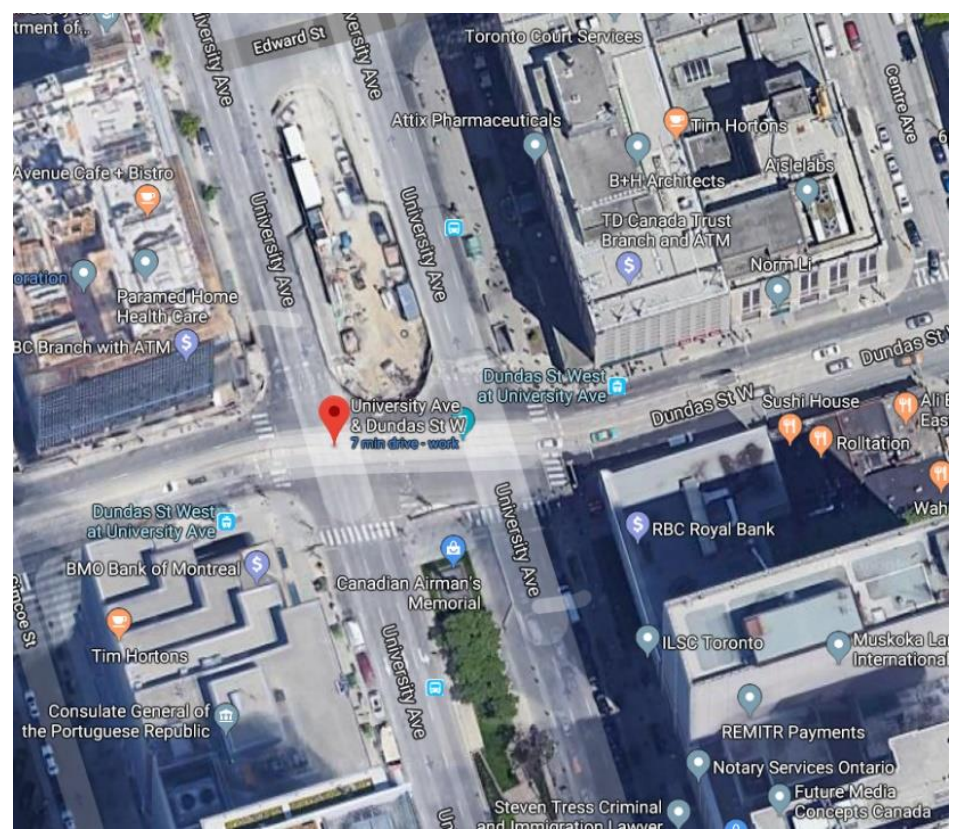

Figure 18 Dundas St at University Avenue (satellite view)

In this scenario Dundas St at University Ave was analyzed the intersection by observing the changes that will occur when we change the posted speed by $10 \mathrm{~km} / \mathrm{hr}$. This change was made to explore the effects of speed on different MPRs. In figure 20 it can be observed that there is not very much change in the queue length on the Dundas St and University Ave when compared to the old result in Figure 17 the graph looks same. But when we plot the bar graph, we can see a minor change in the queue length on Adelaide St, Queen St, Elm St and Gerrard St. It can also be observed that the queue length significantly increased on Dundas St. This may be because of the geometry of the intersection and change in number of lanes at the intersection. 


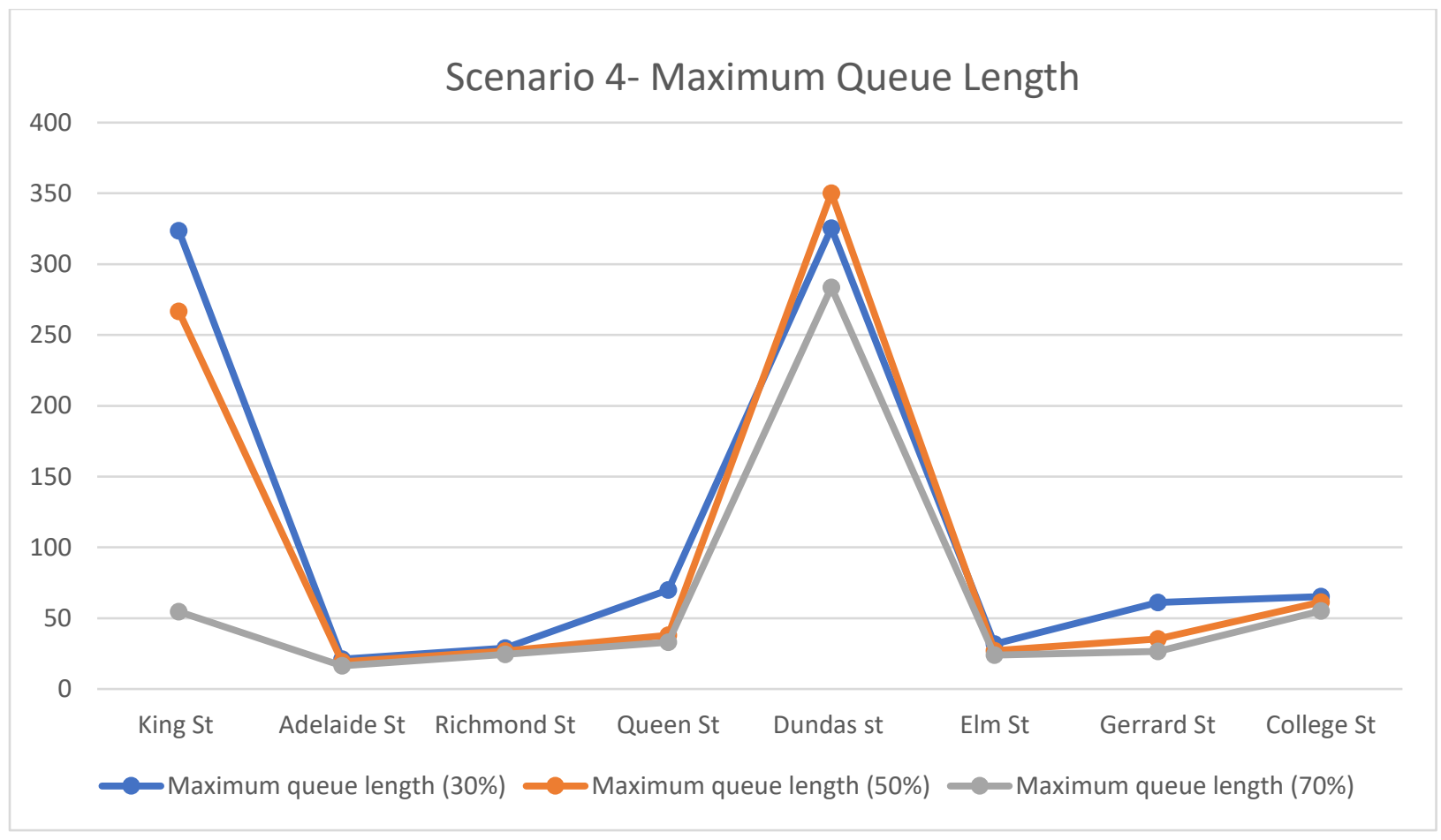

Figure 19 Scenario 4 Maximum Queue Length

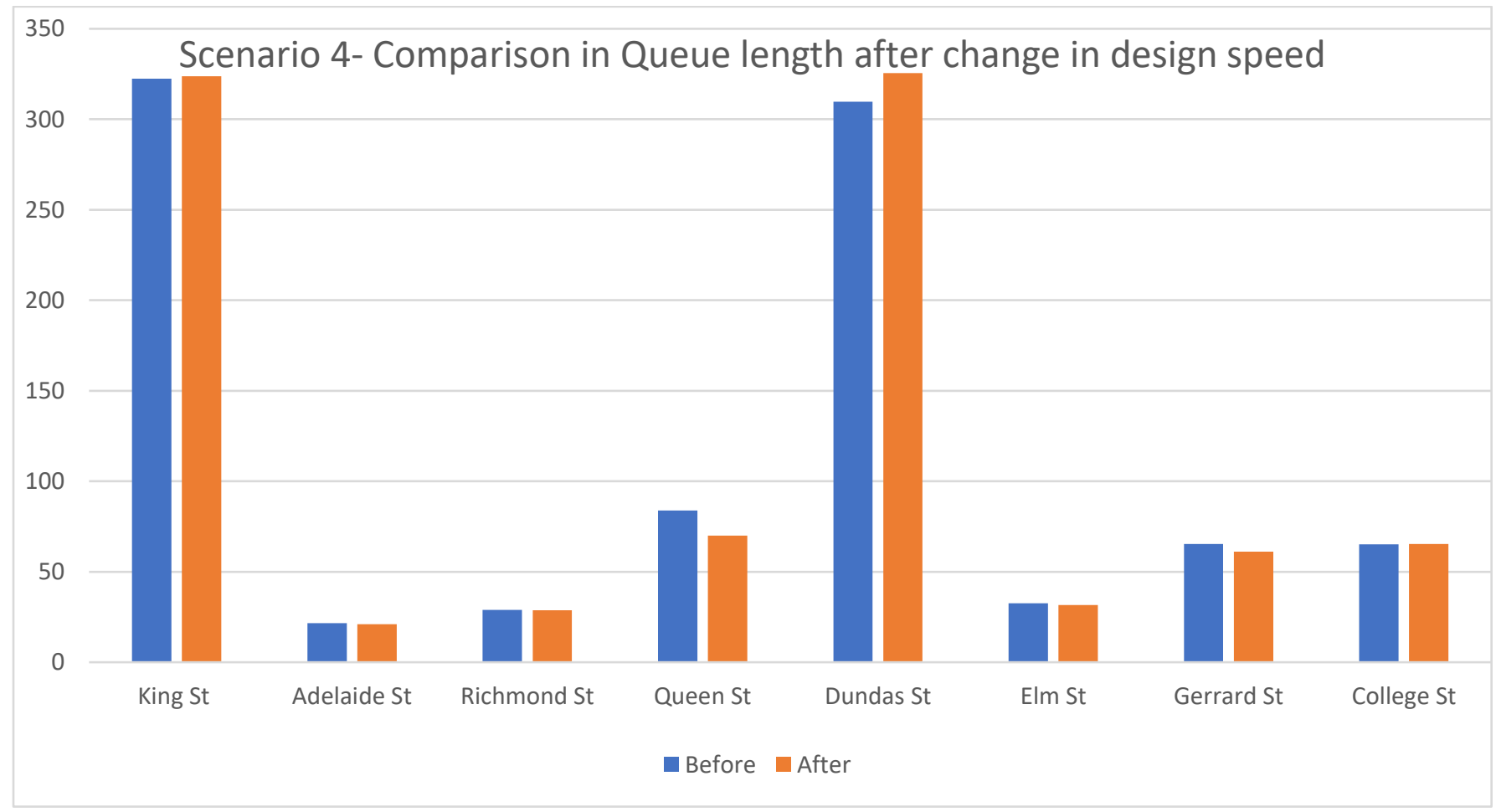

Figure 20 Scenario 4 Effect of Design speed change 
From figure 21 above it can be observed that with the change in design speed there is a minor reduction in the queue length by $2.7 \%, 15 \%, 3 \% \& 6 \%$ respectively, on Adelaide st, Queen St, Elm St and Gerrard St.

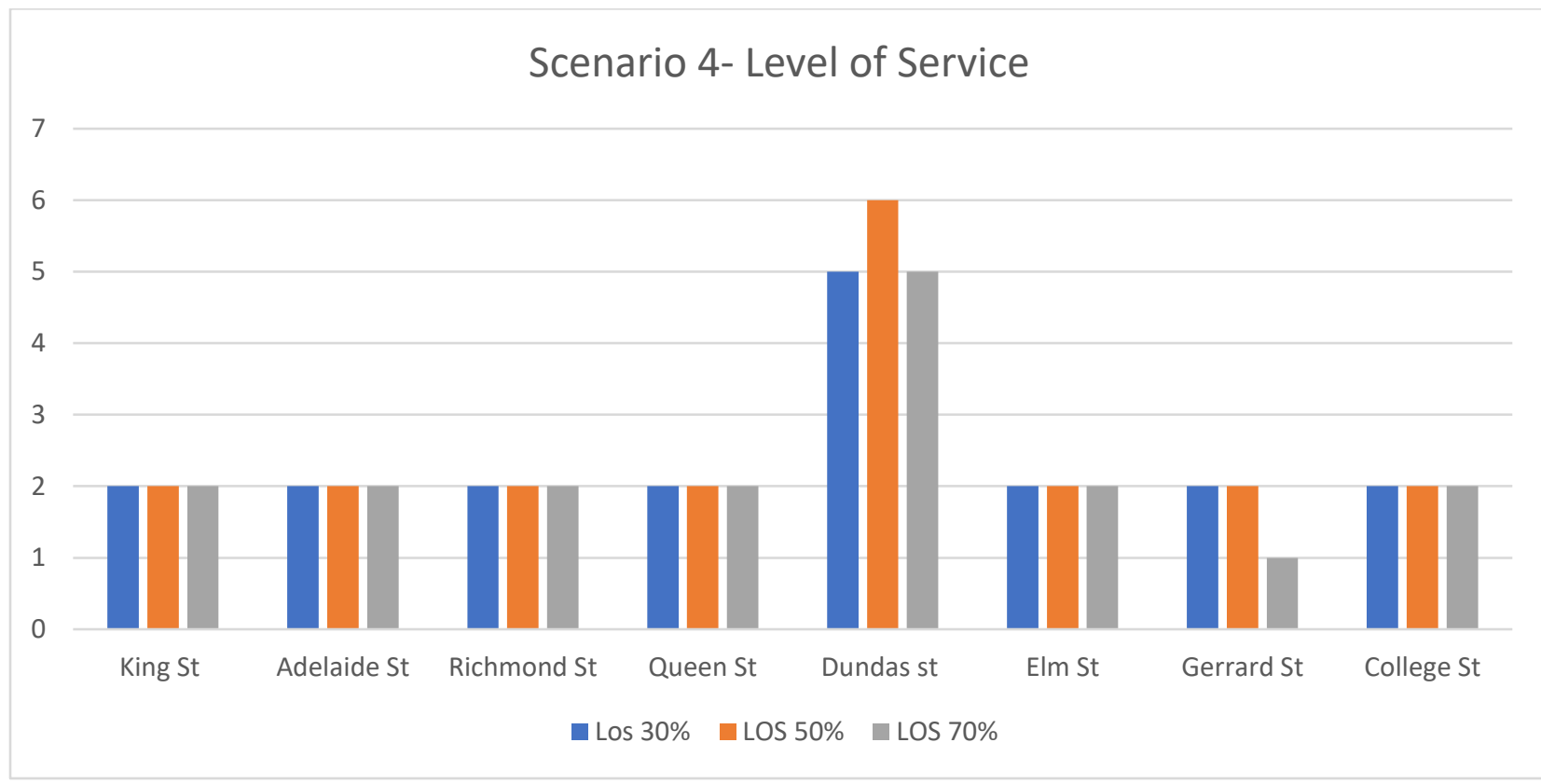

Figure 21 Scenario 4 Level of Service

Regarding LOS as shown in Figure 22 ( 1 being LOS $=\mathrm{A} \& 6$ being LOS $=\mathrm{F}$ ), there is barely any change in the LOS even after we increase the speed. LOS is determined by a range of densities for example level of service $\mathrm{C}$ has a density from $11 \mathrm{veh} / \mathrm{km} / \mathrm{ln}$ to $16 \mathrm{veh} / \mathrm{km} / \mathrm{ln}$. Due to this range, density may have increased on the intersection but not increased by a significant amount to show change in LOS.

Overall, we noticed that in the case of $20 \%$ growth rate changing the speed would not have a huge impact on any of our parameters analyzed mainly because of two reasons; First, with the increase in vehicles on the road no matter how much changes we make on speed it would not be sufficient to help reduce vehicles delays, queue length or improve level of service. Secondly, autonomous vehicles without connectivity don't show much improvements. Although the vehicle can drive 
itself closely, but without the ability of it to connect to other vehicles and the infrastructure to determine if there is congestion downstream of its path and change its routes, its affect is similar to a normal vehicle on the road and would not improve the LOS of the intersection.

\subsubsection{Scenario 5 analysis and results}

In this scenario, we optimized the cycle length for the entire network using genetic algorithm with an upper limit of $140 \mathrm{sec}$ and lower limit of $60 \mathrm{sec}$ and analyzed the effect of this change on Dundas St. at University Ave.

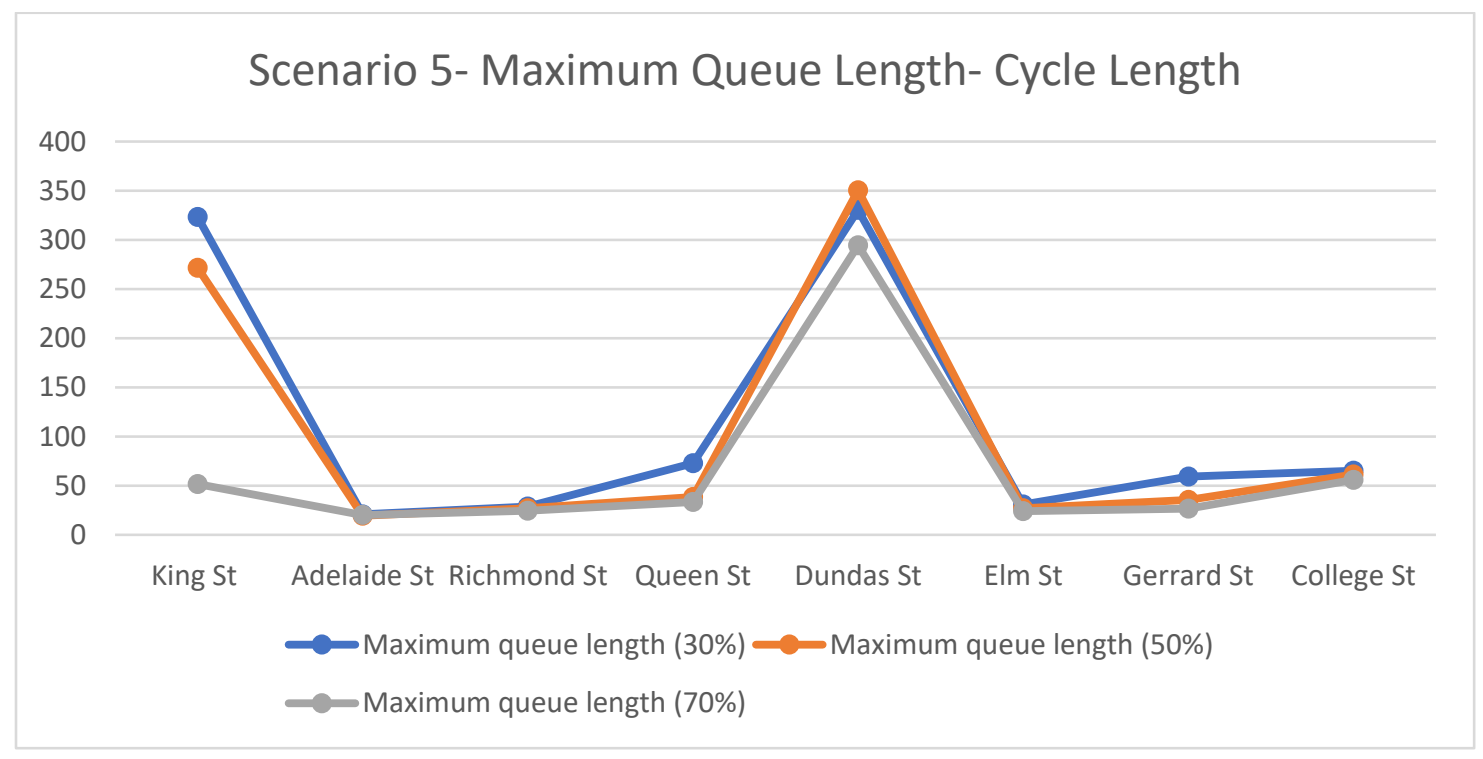

Figure 22 Scenario 5 Maximum Queue Length

From figure 23 above we can see there was not much change when it comes to queue length for the $30 \%$ MPR and $50 \%$ however for the $70 \%$ there was significant improvements on some intersections in our network but when it comes to University and Dundas a small change occurred. This small change can be justified in figure 24 . 


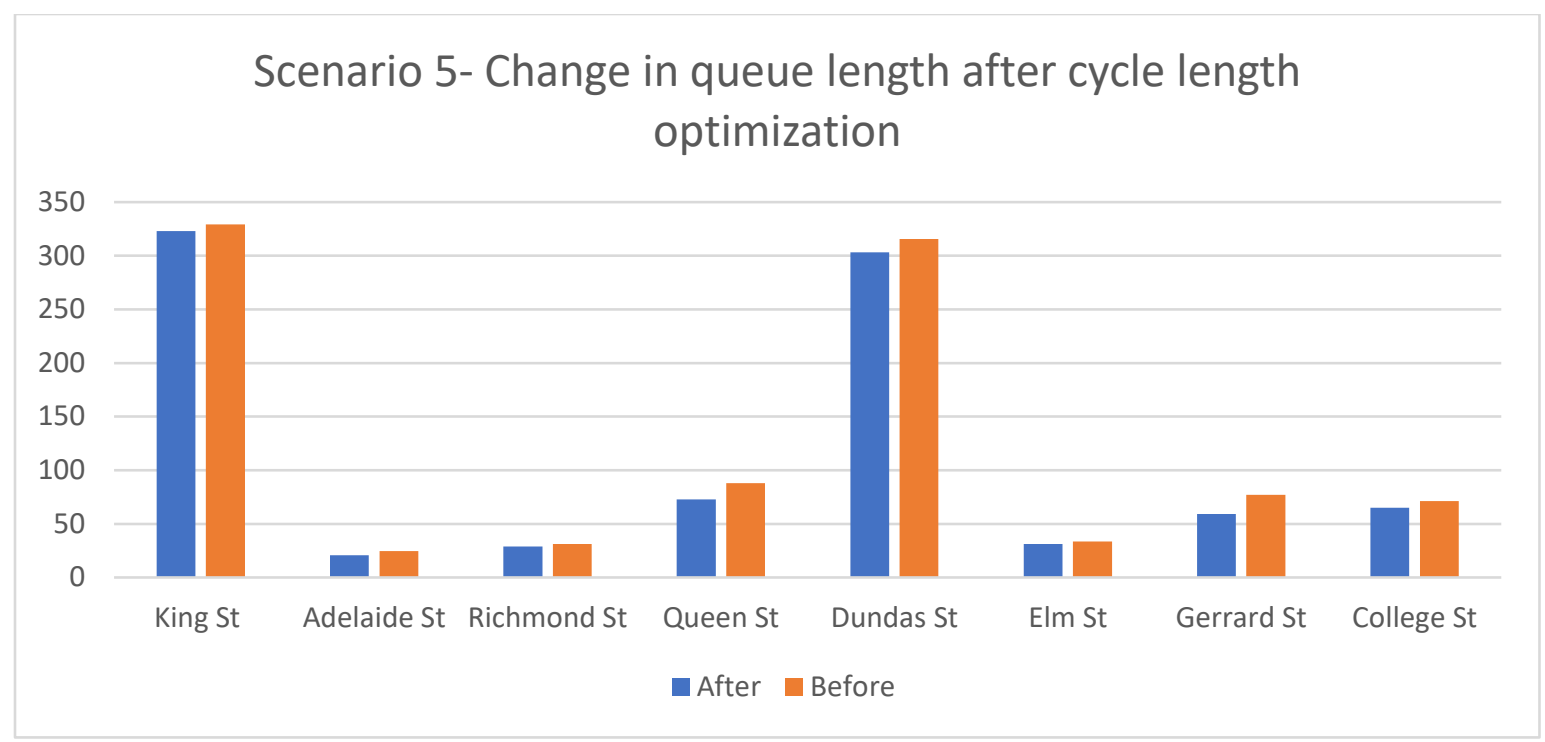

Figure 23 Scenario 5 Change in queue length after cycle length optimization

As shown in figure 24, even after optimizing the network cycle length there wasn't much change from the previous cycle length determined by the City of Toronto. A reasonable result since we are using realistic data and the City must have applied the optimal cycle lengths to the network already to have it operating in a good performance rate.

Therefore, as one can see from the results of vehicle delay and stop delay not much changes occurred when it comes to changes in cycle lengths as a result of optimizing the network. Since the current signals in Toronto already operate at their optimal cycle lengths so very minor changes up to $7 \%$ can be observed. 


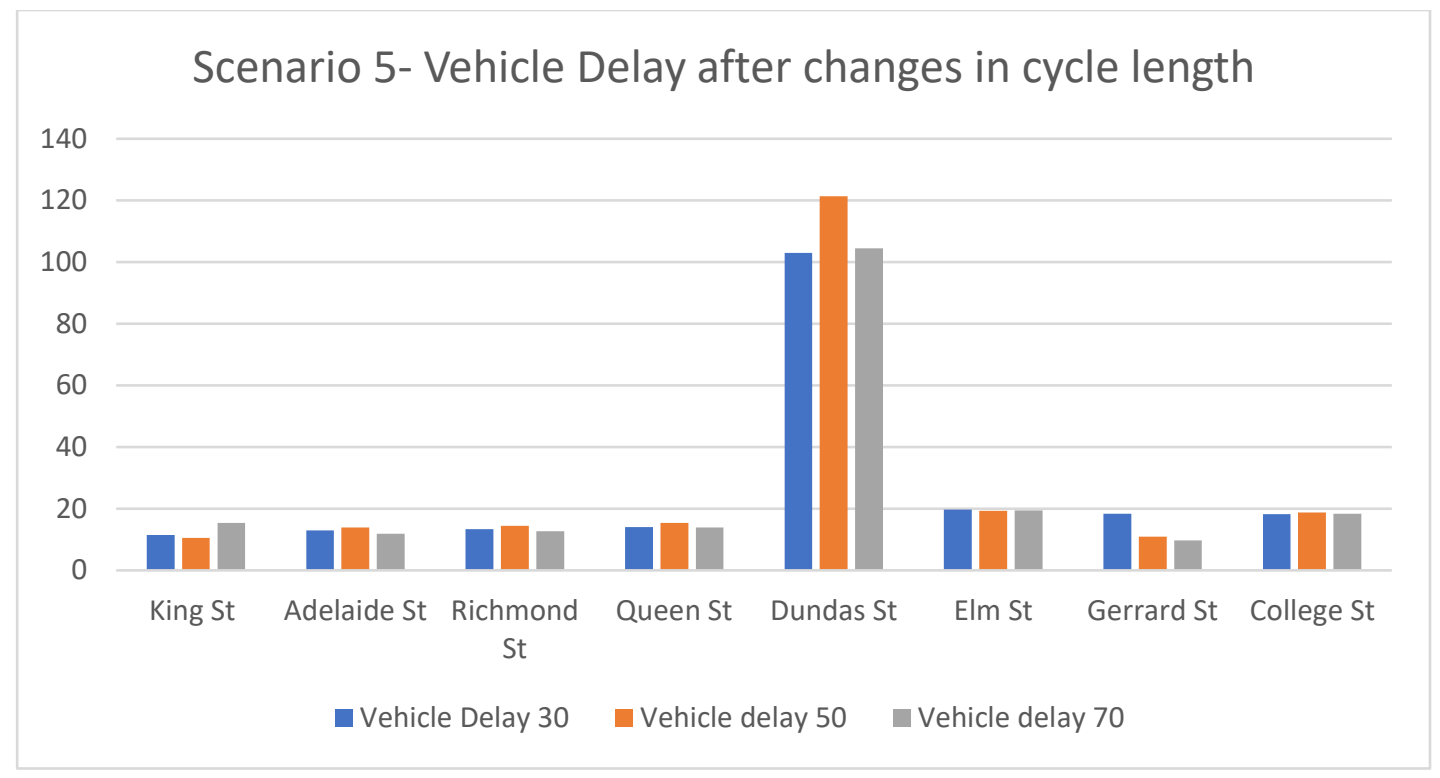

Figure 24 Scenario 5 Vehicle Delay after changes in cycle length

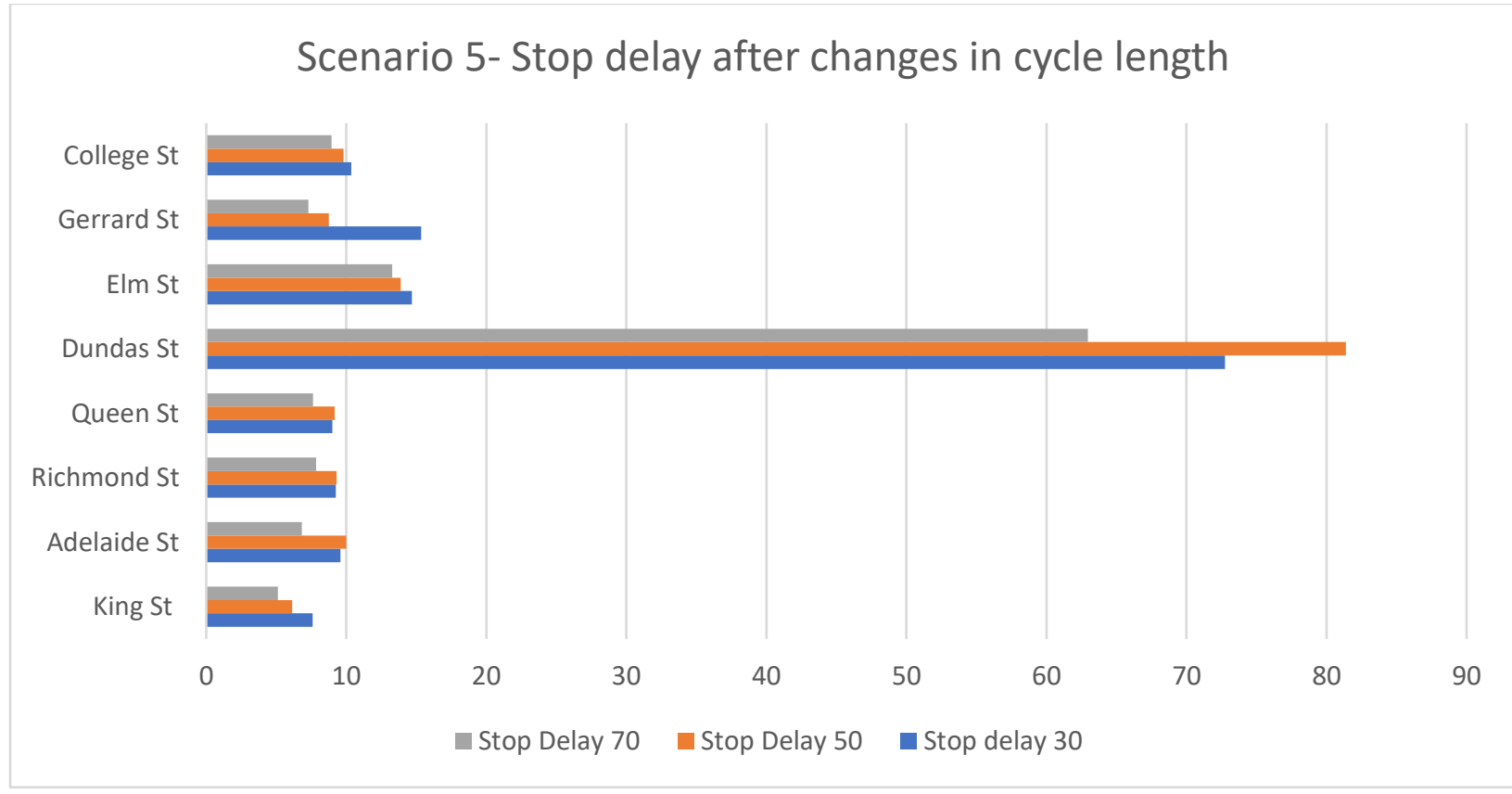

Figure 25 Scenario 5 Stop Delay after changes in cycle length

In general, the city signals are currently operating at near optimal cycle lengths timings so not much change occurred when it came to reducing queue length, vehicle delay and stop delay. Therefore, other options which includes intelligent traffic signal should be explored to try to reduce 
these parameters. A key to improve the city network is connectivity and installation of smart signals which will reduce the vehicle travel time and the other global factors. Overall, it is critical to recognize that autonomous vehicles alone without connectivity won't show a significant improvement in our networks. Therefore, there is a need for investing in upgrade of our current infrastructure to accommodate CAVs is essential to see the desirable improvements in our traffic network. 


\section{5 - Summary of Recommendations}

The following table 4 summarizes the recommendations and suggestions talked earlier in the report.

It also maps the key stakeholders that could be critical in implementing them, and some of the guidance and planning documents which could take them into account. 
Table 4 Table of Summary

\begin{tabular}{|c|c|c|c|c|}
\hline Item & Category & Summary & Key Stakeholders & Key Documents \\
\hline 1 & $\begin{array}{l}\text { Traffic } \\
\text { Management } \\
\text { Measures }\end{array}$ & $\begin{array}{l}\text { Consider methods to communicate } \\
\text { areas that are affected by roadworks } \\
\text { to CAV's to act as failsafe for vehicle } \\
\text { systems. }\end{array}$ & $\begin{array}{l}\text { 1. AV mapping providers } \\
\text { 2.Highway Authorities } \\
\text { 3.Road work-operators } \\
\text { 4.Telecom providers } \\
\text { 5.Transport Canada }\end{array}$ & $\begin{array}{l}\text { 1. Traffic Management Act } \\
\text { 2. Ontario Traffic Manual (Book } \\
7,11)\end{array}$ \\
\hline 2 & $\begin{array}{l}\text { Traffic } \\
\text { Management } \\
\text { Measures }\end{array}$ & $\begin{array}{l}\text { A methodology should be developed } \\
\text { to establish the extent to which traffic } \\
\text { management sites are CAV } \\
\text { compliant, and these could be } \\
\text { marked on the digital map. } \\
\text { Consideration could be given to style } \\
\text { and machine readability of markings, } \\
\text { barrier, cones and general traffic } \\
\text { control measures. }\end{array}$ & $\begin{array}{l}\text { 1. AV mapping providers } \\
\text { 2.Highway Authorities } \\
\text { 3.Road work-operators } \\
\text { 4.Telecom providers } \\
\text { 5.Transport Canada }\end{array}$ & $\begin{array}{l}\text { 1. Traffic Management Act } \\
\text { 2.Ontario Traffic Manual (Book } \\
7,11)\end{array}$ \\
\hline 3 & $\begin{array}{l}\text { Traffic } \\
\text { Management } \\
\text { Measures }\end{array}$ & $\begin{array}{l}\text { Detailed information could be } \\
\text { provided on road layout and } \\
\text { expected vehicle behaviour on traffic } \\
\text { management measures (e.g. stop at } \\
\text { traffic signal, merge in turn, use } \\
\text { contraflow lane etc.) }\end{array}$ & $\begin{array}{l}\text { 1. AV mapping providers } \\
\text { 2.Highway Authorities } \\
\text { 3.Road work-operators } \\
\text { 4.Telecom providers } \\
\text { 5.Transport Canada }\end{array}$ & $\begin{array}{l}\text { 1. Traffic Management Act } \\
\text { 2.Ontario Traffic Manual }\end{array}$ \\
\hline
\end{tabular}




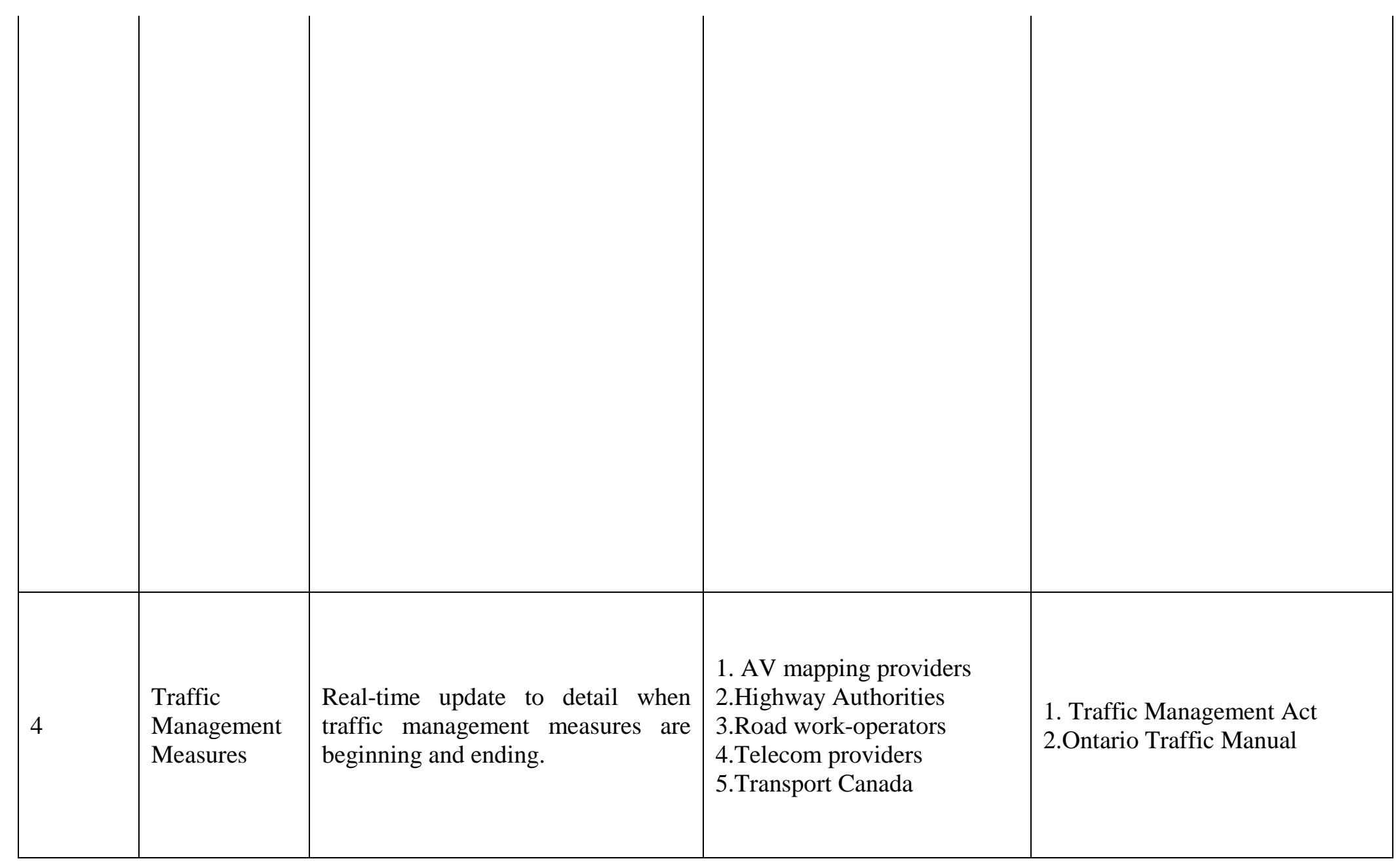




\begin{tabular}{|c|c|c|c|c|}
\hline 5 & $\begin{array}{l}\text { Traffic } \\
\text { Management } \\
\text { Measures }\end{array}$ & $\begin{array}{l}\text { New roads and major junctions could } \\
\text { be connected to electricity and fibre- } \\
\text { optic/copper where practicable. }\end{array}$ & $\begin{array}{l}\text { 1.Highway Authorities } \\
\text { 2.Transport Canada }\end{array}$ & $\begin{array}{l}\text { 1. Traffic Management Act } \\
\text { 2.Ontario Traffic Manual }\end{array}$ \\
\hline 6 & $\begin{array}{l}\text { Traffic } \\
\text { Management } \\
\text { Measures }\end{array}$ & $\begin{array}{l}\text { Develop "CAV Compliant First } \\
\text { Respondents" procedure for road } \\
\text { incidents. }\end{array}$ & $\begin{array}{l}\text { 1. CAV tech developers } \\
\text { 2.Highway Authorities } \\
\text { 3.Road work operators } \\
\text { 4.Emergency Services } \\
\text { 5.Transport Canada }\end{array}$ & $\begin{array}{l}\text { 1. Traffic Management Act } \\
\text { 2.Ontario Traffic Manual }\end{array}$ \\
\hline 7 & $\begin{array}{l}\text { Traffic } \\
\text { Management } \\
\text { Measures }\end{array}$ & $\begin{array}{l}\text { Develop a warning sign/signal that } \\
\text { can used to warn CAVs of danger } \\
\text { ahead. }\end{array}$ & $\begin{array}{l}\text { 1. CAV tech developers } \\
\text { 2.Highway Authorities } \\
\text { 3.Road work-operators } \\
\text { 4.Emergency Services } \\
\text { 5.Transport Canada }\end{array}$ & $\begin{array}{l}\text { 1. Traffic Management Act } \\
\text { 2.Ontario Traffic Manual }\end{array}$ \\
\hline 8 & $\begin{array}{l}\text { Traffic } \\
\text { Management } \\
\text { Measures }\end{array}$ & $\begin{array}{l}\text { Research into how humans can direct } \\
\text { CAVs with hand signals, which } \\
\text { could be used by incident first } \\
\text { response teams. }\end{array}$ & $\begin{array}{l}\text { 1. CAV tech developers } \\
\text { 2.Emergency Services } \\
\text { 3.Transport Canada }\end{array}$ & $\begin{array}{l}\text { 1. Traffic Management Act } \\
\text { 2.Ontario Traffic Manual }\end{array}$ \\
\hline
\end{tabular}




\begin{tabular}{|c|c|c|c|c|}
\hline 9 & $\begin{array}{l}\text { Traffic } \\
\text { Management } \\
\text { Measures }\end{array}$ & $\begin{array}{l}\text { Undertake review of Traffic Signs } \\
\text { Manual. Phasing out traffic } \\
\text { management measures which are } \\
\text { difficult for CAVs to interpret. }\end{array}$ & $\begin{array}{l}\text { 1. CAV tech developers } \\
\text { 2.Transport Canada }\end{array}$ & $\begin{array}{l}\text { 1. Traffic Management Act } \\
\text { 2.Ontario Traffic Manual }\end{array}$ \\
\hline 10 & $\begin{array}{l}\text { Traffic } \\
\text { Management } \\
\text { Measures }\end{array}$ & $\begin{array}{l}\text { Investigate procedures to ensure } \\
\text { hardware is standardised and well } \\
\text { maintained, particularly if used as } \\
\text { failsafe for CAV systems. }\end{array}$ & $\begin{array}{l}\text { 1. CAV tech developers } \\
\text { 2.Highway Authorities } \\
\text { 3.Road work operators } \\
\text { 4.Emergency Services } \\
\text { 5.Transport Canada }\end{array}$ & $\begin{array}{l}\text { 1. Traffic Management Act } \\
\text { 2.Ontario Traffic Manual }\end{array}$ \\
\hline 11 & $\begin{array}{l}\text { Traffic } \\
\text { Signals }\end{array}$ & $\begin{array}{l}\text { The duration of the yellow change } \\
\text { interval should be calculated } \\
\text { according to the ITE's kinematic } \\
\text { equation. A shorter duration of the } \\
\text { yellow change interval will adversely } \\
\text { impact the safety of both } \\
\text { conventional vehicles and the AV. }\end{array}$ & $\begin{array}{l}\text { 1. CAV tech developers } \\
\text { 2.Transport Canada }\end{array}$ & $\begin{array}{l}\text { 1. Ontario Traffic Manual book } \\
\text { 2. Canadian Capacity Guide }\end{array}$ \\
\hline 12 & $\begin{array}{l}\text { Traffic } \\
\text { Signals }\end{array}$ & $\begin{array}{l}\text { The red clearance time should be } \\
\text { calculated using the posted speed } \\
\text { limit instead of the } 85 \text { th percentile } \\
\text { speed. }\end{array}$ & $\begin{array}{l}\text { 1. CAV tech developers } \\
\text { 2.Transport Canada }\end{array}$ & $\begin{array}{l}\text { 1. Ontario Traffic Manual book } \\
\text { 2. Canadian Capacity Guide }\end{array}$ \\
\hline
\end{tabular}




\begin{tabular}{|c|c|c|c|c|}
\hline 13 & $\begin{array}{l}\text { Traffic } \\
\text { Signals }\end{array}$ & $\begin{array}{l}\text { The programming of the on-board } \\
\text { computers shall consider deploying } \\
\text { adjustable delay times based on local } \\
\text { driving conditions (provincial, } \\
\text { territorial, and municipal) and driver } \\
\text { behavior. }\end{array}$ & $\begin{array}{l}\text { 1. CAV tech developers } \\
\text { 2.Transport Canada }\end{array}$ & $\begin{array}{l}\text { 1. Ontario Traffic Manual book } \\
\text { 2. Canadian Capacity Guide }\end{array}$ \\
\hline 14 & $\begin{array}{l}\text { Road Signs } \\
\text { and Markings }\end{array}$ & $\begin{array}{l}\text { With road markings forming the } \\
\text { 'rails of automated steering systems', } \\
\text { the procedures for maintenance of } \\
\text { road markings may need to be } \\
\text { improved and funding increased. }\end{array}$ & $\begin{array}{l}\text { 1. CAV tech developers } \\
\text { 2.Transport Canada }\end{array}$ & $\begin{array}{l}\text { 1. Ontario Traffic Manual book } \\
11\end{array}$ \\
\hline 15 & $\begin{array}{l}\text { Road Signs } \\
\text { and Markings }\end{array}$ & $\begin{array}{l}\text { Consider ongoing global research } \\
\text { into appropriate road markings for } \\
\text { CAVs }\end{array}$ & $\begin{array}{l}\text { 1. Highway Authorities } \\
\text { 2.Transport Canada }\end{array}$ & $\begin{array}{l}\text { 1. Ontario Traffic Manual book } \\
11\end{array}$ \\
\hline 16 & $\begin{array}{l}\text { Road Signs } \\
\text { and Markings }\end{array}$ & $\begin{array}{l}\text { With some systems relying on } \\
\text { visually detecting and interpreting } \\
\text { traffic signs it could be important to } \\
\text { ensure that they are maintained to a } \\
\text { high standard in terms of cleanliness, } \\
\text { clarity, deterioration, non- } \\
\text { ambiguous positioning, and } \\
\text { obscuration. }\end{array}$ & $\begin{array}{l}\text { 1. Highway Authorities } \\
\text { 2.Transport Canada }\end{array}$ & $\begin{array}{l}\text { 1. Ontario Traffic Manual book } \\
11\end{array}$ \\
\hline
\end{tabular}


It may be necessary to work with 1. Highway Authorities

relevant stakeholders to ensure 2.Transport Canada

1. Ontario Traffic Manual book

unadopted roads are checked and

certified for use by CAVs. 


\section{6 - Conclusions}

There are several potential benefits of automated vehicles such as improved safety, increased accessibility, environmental benefits etc. But in order to attain the complete benefits of autonomous vehicles, this technology when available in the market must have the proper infrastructure provided by governments/cities for them to operate at their full potential without causing problems. This could involve revising not only the planning guidance policies but also upgrading documents to accommodate this new technology. New legislation is creating opportunities for these cars to prove their viability through allowing testing's across Canada. The ongoing research and testing will only prove to advance the acceptance of autonomous cars and invest in upgrading our existing infrastructure further. Through extensive literature review and results from our case study we developed a table that summarizes points for various infrastructure types.

The table identifies over 20 action points which fall into: traffic management measures, traffic signals, car parking, and crossings and junctions, accompanied by identifying key stake holder and key documents that need to be adjusted. For Example, regarding "Traffic Signals" three major adjustments were recommended. One of them is that the duration of the yellow change interval should be calculated according to the ITE's kinematic equation. A shorter duration of the yellow change interval will adversely impact the safety of both conventional vehicles and the autonomous vehicles. The key documents that discuss signal timings and need to be upgraded are Ontario Traffic Manual book and The Canadian Capacity Guide.

It is also essential to recognize from our case study on Toronto downtown network, that autonomous vehicles at low MPR's do not show the prominent improvements as expected. Improvements can be seen from $50-70 \%$ and after 70\% MPR is where the max. improvements 
occur and stay consistent until full saturation of the market occurs. In addition, autonomy without connectivity won't improve the performance of our network as seen from the results obtained from our case study. Therefore, there is a need to invest in upgrading our current infrastructure to accommodate CAV's. Then we will witness prominent changes in the performance of our network to the better.

Even with all these findings the number of unknowns relating to Connected and Automated vehicles and their ongoing development makes this area one that is constantly changing. It is crucial that authorities continue to monitor the areas identified in this report, and to work closely with infrastructure providers, AV technology developers and other stakeholders to understand their requirements.

We acknowledge that the extend of benefits from AVs are still unknown. Future impacts depend on technological advances, market reactions, and regulatory actions, making it challenging to surely predict impacts to transportation systems. With so many unknowns and potential effects of AVs, it is challenging to anticipate long-term effects with certainty. Nevertheless, some of these impacts should be considered early on, to understand model sensitivity and develop feasible analysis boundaries using simulation and optimization tools. By investigating further scenarios on the network and adding connectivity to autonomous vehicles and developing further analyses, agencies can prepare more active long-range strategies, by defining and evaluating some rational investments and exploring most likely scenarios as technologies appear and mature. Therefore, it is recommended that governments and policy makers here in Ontario should look into investing in the infrastructure needs before the $\mathrm{AVs}$ are on the streets. 


\section{References}

[1] A. D. Febbraro and N. Sacco, "On modelling urban transportation networks via hybrid Petri nets," Control Eng. Pract., vol. 12, no. 10, pp. 1225-1239, Oct. 2004.

[2] D. J. Fagnant and K. Kockelman, "Preparing a nation for autonomous vehicles: opportunities, barriers and policy recommendations," Transp. Res. Part Policy Pract., vol. 77, pp. 167-181, Jul. 2015.

[3] "Core Components of Transportation," The Geography of Transport Systems, 29-Oct2017. .

[4] "PTV Vissim new," PTV-Group, 21-Feb-2019. [Online]. Available: https://www.ptvgroup.com/en/solutions/products/ptv-vissim/. [Accessed: 21-Apr-2019].

[5] "Automated and Connected Vehicles." [Online]. Available: http://autocaat.org/Technologies/Automated_and_Connected_Vehicles/. [Accessed: 25-Apr2019].

[6] "Wayback Machine," 03-Sep-2017. [Online]. Available: https://web.archive.org/web/20170903105244/https://www.sae.org/misc/pdfs/automated_dri ving.pdf. [Accessed: 20-Apr-2019].

[7] Automated Vehicles for Safety | NHTSA. .

[8] “Connected Vehicles - IEEE Connected Vehicles." [Online]. Available: http://sites.ieee.org/connected-vehicles/ieee-connected-vechicles/connected-vehicles/. [Accessed: 20-Apr-2019].

[9] "Point/Counterpoint: 5G or DSRC for Connected Vehicle Technology," The Eno Center for Transportation. [Online]. Available: https://www.enotrans.org/article/point-counterpoint5g-or-dsrc-for-connected-vehicle-technology/. [Accessed: 20-Apr-2019].

[10] S. Pettigrew, L. Fritschi, and R. Norman, "The Potential Implications of Autonomous Vehicles in and around the Workplace," Int. J. Environ. Res. Public. Health, vol. 15, no. 9, p. 1876, Aug. 2018.

[11] "How Will Autonomous Vehicles Impact How We Build Roads?," For Construction Pros. [Online]. Available: https://www.forconstructionpros.com/asphalt/article/20985026/howwill-autonomous-vehicles-impact-how-we-build-roads. [Accessed: 20-Apr-2019].

[12] "Autonomous-vehicle technology is advancing ever faster - From here to autonomy." [Online]. Available: https://www.economist.com/special-report/2018/03/01/autonomousvehicle-technology-is-advancing-ever-faster. [Accessed: 20-Apr-2019].

[13] P. Koopman and M. Wagner, "Challenges in Autonomous Vehicle Testing and Validation," SAE Int. J. Transp. Saf., 2016.

[14] J. T. Obenberger, "Methodology to Assess Traffic Signal Transition Strategies Employed to Exit Preemption Control," p. 145.

[15] "Victoria Transport Institute - Main Page." [Online]. Available: http://www.vtpi.org/. [Accessed: 19-Apr-2019].

[16] A. Millard-Ball, "Pedestrians, Autonomous Vehicles, and Cities," J. Plan. Educ. Res., vol. 38, no. 1, pp. 6-12, Mar. 2018.

[17] E. Ackerman, CES 2017: Why Every Social Robot at CES Looks Alike. 2017.

[18] L. Kroeger, T. Kuhnimhof, and S. Trommer, "Modelling the Impact of Automated Driving Private Autonomous Vehicle Scenarios for Germany and the US," 2016 Eur. Transp. Conf., 2016. 
[19] N. Ismael, L. M. Lawson, and J. Hartwell, "Relationship between sensory processing and participation in daily occupations for children with autism spectrum disorder: A systematic review of studies that used Dunn's sensory processing framework," Am. J. Occup. Ther., 2018.

[20] D. J. Fagnant and K. Kockelman, "Preparing a Nation for Autonomous Vehicles: Opportunities, Barriers and Policy Recommendations for Capitalizing on Self-Driven Vehicles," Transp. Res. Part A, 2013.

[21] S. E. Shladover, "Connected and automated vehicle systems: Introduction and overview," J. Intell. Transp. Syst. Technol. Plan. Oper., 2018.

[22] A. Alessandrini, A. Campagna, P. D. Site, F. Filippi, and L. Persia, "Automated vehicles and the rethinking of mobility and cities," in Transportation Research Procedia, 2015.

[23] "ITE-2009.pdf." .

[24] "cwbv - OTM Book 12 - Adobe Interactive Ver (2).pdf." Available online http://www.directtraffic.ca/wp-content/uploads/2014/02/Book-121.pdf [Accessed: 20-Apr2019].

[25] "2016_-_Liang_Shi__AutonomousandConnectedCarsHCMEstimatesforFreewaysw[retrieved_2018-1017].pdf.".

[26] Transportation Research Board, HCM 2010: Highway Capacity Manual. 2010.

[27] "tac-atc.ca |." [Online]. Available: https://www.tac-atc.ca/. [Accessed: 20-Apr-2019].

[28] O. Shebeeb and P. Eng, "Helping Autonomous Vehicles at Signalized Intersections," p. 15 .

[29] "1303-004.pdf." J. L. Gattis, Effects of Design Criteria on Local Street Sight Distance, .

[30] "Driver Reaction Time." [Online]. Available: https://www.visualexpert.com/Resources/reactiontime.html. [Accessed: 20-Apr-2019].

[31] I. El-Shawarby, H. Rakha, A. Amer, and C. McGhee, "Characterization of Driver Perception Reaction Time at the Onset of a Yellow Indication," in Advances in Human Aspects of Transportation, vol. 484, N. A. Stanton, S. Landry, G. Di Bucchianico, and A. Vallicelli, Eds. Cham: Springer International Publishing, 2017, pp. 371-382.

[32] M. Green, “'How Long Does It Take to Stop?' Methodological Analysis of Driver Perception-Brake Times," Transp. Hum. Factors, vol. 2, no. 3, pp. 195-216, Sep. 2000.

[33] J. Van Brummelen, M. O’Brien, D. Gruyer, and H. Najjaran, “Autonomous vehicle perception: The technology of today and tomorrow," Transp. Res. Part C Emerg. Technol., vol. 89, pp. 384-406, Apr. 2018.

[34] "ATS40-Future-Proofing-Infrastructure-for-CAVs.pdf." [Online] https://s3-eu-west1.amazonaws.com/media.ts.catapult/wp-content/uploads/2017/04/25115313/ATS40-FutureProofing-Infrastructure-for-CAVs.pdf .

[35] A. Kalatian, A. Sobhani, and B. Farooq, "Analysis of distracted pedestrians' waiting time: Head-Mounted Immersive Virtual Reality application,” p. 7.

[36] IBR - Institut für Betriebssysteme und Rechnerverbund, $k$-Stacks: Minimizing Parking Area in Automated Valet Parking. .

[37] Sunny Spot, Audi Self Driving Auto Parking. [Online] https://www.youtube.com/watch?v=5YVfb779tUo.

[38] "Autonomous Vehicles - Arrow street." [Online] http://www.arrowstreet.com/tag/autonomous-vehicles/ .

[39] L. Alfaseeh, S. Djavadian, and B. Farooq, "Impact of Distributed Routing of Intelligent Vehicles on Urban Traffic,” ArXiv180908197 Phys., Sep. 2018. 